\title{
Herramientas para el monitoreo y sistema de alerta de floraciones de cianobacterias nocivas: Río Uruguay y Río de la Plata
}

\author{
Monitoring tools and early warning system for harmful \\ cyanobacterial blooms: Río Uruguay and Río de la Plata
} Kruk, Carla ${ }^{*(1)(2)}$, Segura, Angel (2)(3), Nogueira, Lucía ${ }^{(2)}$, Carballo, Carmela ${ }^{(1)(5)}$, Martínez de la Escalera, Gabriela ${ }^{(4)}$,
Calliari, Danilo $^{(5)(6)}$, Ferrari, Graciela ${ }^{(7)}$, Simoens, Macarena (7), Cea, Jacqueline ${ }^{(7)}$, Alcántara, Ignacio ${ }^{(2)(4)}$, Vico, Paula ${ }^{(4)}$,
Míguez, Diana ${ }^{(7)}$ y Piccini, Claudia ${ }^{*(2)(4)}$.
${ }^{(1)}$ Sección Limnología, IECA, Facultad de Ciencias, UdelaR - ${ }^{(2)}$ Grupo de Ecología Funcional de Sistemas Acuáticos,
UdelaR - ${ }^{(3)}$ MAREN, CURE-Rocha ${ }^{\left({ }^{(4)}\right.}$ Microbiología, IIBCE, MEC - ${ }^{(5)}$ PDU Ecología Funcional de Sistemas Acuáticos,
CURE-Rocha - ${ }^{(6)}$ Oceanología y Ecología Marina, Facultad de Ciencias, UdelaR - (7) Laboratorio Tecnológico del Uruguay

Contacto: ckruk@yahoo.com; cpiccini@iibce.edu.uy

RECIBIDO: 2/9/2015 - APROBADO: 14/12/2015

\begin{abstract}
Resumen
Las floraciones de cianobacterias potencialmente tóxicas son uno de los problemas más difundidos en los sistemas acuáticos a nivel global. Sin embargo, es necesario desarrollar programas de monitoreo sensibles y directamente aplicables a la predicción de las floraciones y su gestión. Con este objetivo se combinaron conceptos ecológicos y genéticos para generar herramientas para el monitoreo de cianobacterias. Se utilizaron dos aproximaciones: agrupación de organismos en grupos funcionales basados en morfología y análisis moleculares (PCR cuantitativo en tiempo real) que indican presencia de genes que codifican para la expresión de cianotoxinas (mcy). Para evaluar las herramientas se realizaron seis campañas de muestreo bimensuales (2013-2014) en seis estaciones con dos sitios en cada una, a lo largo del Río Uruguay y del Estuario Río de la Plata, desde Salto Grande hasta Punta del Este. Se observó un gradiente marcado en las variables meteorológicas, físico-químicas, y mayores abundancias de organismos planctónicos en Salto Grande y Punta del Este. Se encontró la presencia en todo el gradiente de poblaciones tóxicas, con mayor abundancia en Salto, particularmente del complejo Microcystis aeruginosa (CMA). Las variables ambientales más importantes en determinar el gradiente ambiental y las variaciones en las variables biológicas fueron la salinidad, la temperatura, el viento y la turbidez. Los resultados de los nuevos indicadores (presencia en red del CMA y genes mcy) estuvieron correlacionados con los tradicionales (ej. clorofila-a) en los casos de floraciones más severas, y fueron sustantivamente más sensibles que los tradicionales en situaciones de bajas abundancias. La conjunción de los resultados se aplicó a la construcción de un protocolo de monitoreo y un sistema de alerta.
\end{abstract}

Palabras clave: Floraciones, grupos funcionales, genotipos tóxicos, gradiente ambiental, protocolo de monitoreo, sistema de alerta.

\begin{abstract}
Potentially hazardous cyanobacterial blooming constitutes one of the most widespread problems experienced by aquatic systems worldwide. However, the development of novel monitoring methods sensitive enough to be directly applicable to predict and manage blooming events is required. In order to fulfill this goal, both ecological and genetic concepts were combined to generate novel cyanobacteria monitoring tools. Two approaches were used: grouping organisms into functional groups and utilizing molecular analysis (real time quantitative PCR) as indicators of the presence of genes that encode the expression of cyanotoxins (mcy). Six bi-monthly sampling campaigns were performed to evaluate the suitability of these tools (2013-2014) at six locations composed of two sites each one, ranging downstream from Salto Grande, at the River Uruguay, to Punta del Este, at the Estuary River Plate. A remarkable gradient was observed in the meteorological, physical and chemical variables, as well as higher abundances in planktonic organisms both in Salto Grande and in Punta del Este. The most abundant population of toxic species in the whole gradient were found in Salto, and in particular those belonging to the Microcystis aeruginosa complex (MAC). The most relevant environmental variables to determine the gradient and the variation in biological variables were: salinity, temperature, wind and turbidity. The results of the new indicators (presence of MAC in the plankton net and mcy genes) were correlated with the traditional ones (e.g. chlorophyll-a) demonstrating being much more sensitive in low abundance situations. The conjunction of results was applied to the construction of a monitoring and early warning system protocol.
\end{abstract}

Keywords: Blooms, functional groups, toxic genotypes, environmental gradient, monitoring protocol, alert system. 


\section{Introducción}

\section{Necesidad y dificultades del monitoreo de floraciones fitoplanctónicas}

La pérdida de calidad de agua y el desarrollo de floraciones nocivas de fitoplancton son problemáticas actuales de Uruguay y del mundo (Paerl y Huisman, 2008; Vidal y Kruk, 2008; Vidal y Britos, 2012). Las floraciones son el crecimiento excesivo de una o pocas especies en relación a su concentración original (Smayda, 1997; Chorus y Bartram, 1999; Reynolds, 2006). Estas disminuyen la calidad del agua y la biodiversidad, y la situación es más adversa aún cuando producen toxinas. En los ecosistemas de agua dulce las toxinas son producidas principalmente por cianobacterias (Pérez, et al., 1999; De León y Yunes, 2001; Aubriot, et al., 2009; Chorus, 2012). El aumento de actividades agropecuarias con uso intensivo de fertilizantes y el vertido de desechos no procesados al agua son una de las principales causas del aumento de la frecuencia e intensidad de las floraciones (Mazzeo, et al., 2002; Chalar, 2009; Rodríguez-Gallego, 2010). Son importantes también las modificaciones físicas, como la construcción de represas, la canalización y la destrucción de la vegetación ribereña (Conde, et al., 2002a; Conde, et al., 2002b). Las floraciones generan inconvenientes sanitarios y sociales, así como grandes pérdidas económicas (DINAMA, 2009; OSE, 2009; Chorus, 2012).

La preocupación a nivel mundial sobre las floraciones ha creado la necesidad de medidas de manejo exitosas. Para ello es necesario desarrollar monitoreos que generen información rápida, fácil de interpretar y útil para la predicción de la ocurrencia e intensidad de las floraciones. Existen varias especies de fitoplancton y cianobacterias que pueden desarrollar floraciones. Cada especie puede producir más de un tipo de toxina y dicha producción varía con distintas condiciones ambientales, entre distintas cepas y según el estado fisiológico de las células (Piccini, et al., 2011; Martigani, 2012; Piccini, et al., 2013).

Tradicionalmente se han utilizado estimadores globales de la comunidad del fitoplancton para su monitoreo, como por ejemplo la concentración de clorofila-a (Vollenweider, 1976; Scheffer, et al., 2003). Estos indicadores son buenas herramientas por su rapidez y simplicidad, pero no consideran diferentes respuestas y efectos (toxicidad, riesgo sanitario) causados por la presencia de distintas especies. Por estas razones es sustancial realizar adecuadas identificaciones taxonómicas de las especies. Sin embargo, la inspección microscópica es trabajosa y la ocurrencia de especies problema no es condición suficiente para la presencia de toxinas en el agua. Aún más, el hecho de que distintas especies tengan distintas preferencias ambientales $y$, por lo tanto, distintas respuestas al ambiente, hace que su predicción a partir de datos ambientales sea prácticamente imposible (Huisman y Weissing, 2001). Es necesario desarrollar herramientas que contemplen los mecanismos ecológicos que controlan el funcionamiento de las comunidades (Le Quéré, et al., 2005) pero sinteticen el comportamiento de las cientos de especies de fitoplancton que pueden ocurrir simultáneamente (Kruk, et al., 2011) y consideren la potencialidad de producir toxinas (Piccini, et al., 2013). La combinación de agrupaciones de las especies en grupos funcionales (Kruk, et al., 2010; Reynolds, 2012) con aproximaciones que estimen la potencialidad de producir toxinas, por ejemplo mediante la identificación de genotipos tóxicos, surge como una alternativa relevante (Dittmanna y Börner, 2005).

\section{Microcystis y microcistinas}

Las microcistinas son una de las familias de toxinas más conocidas, estudiadas y una de las más frecuentemente detectadas. Es producida por una gran variedad de géneros, incluyendo algunas de las especies más comúnmente encontradas en floraciones, como es el caso de Microcystis aeruginosa (Orden Chroococcales) (De León y Yunes, 2001; González-Piana, et al., 2011) que forma densas floraciones superficiales en todo el mundo incluyendo Uruguay (De León y Yunes, 2001; Huisman y Hulot, 2005) y forma parte del grupo funcional basado en morfología VII (Kruk, et al., 2010). Existen distintos métodos de cuantificación de cianotoxinas en muestras naturales, pero muchos de ellos presentan desventajas como la reactividad cruzada, los altos costos y el uso de elementos radiactivos (Brena y Bonilla, 2009). Si bien en Uruguay se cuenta con la capacidad técnica para detectar cianotoxinas, esta es todavía restringida a microcistinas totales y LR. Es necesario el desarrollo de nuevas metodologías para complementar las existentes, considerando la importancia de que estos métodos sean rápidos, sensibles, confiables, generales y de mediano o bajo costo. Entre los métodos moleculares se encuentra la detección mediante PCR (reacción en cadena de la polimerasa) de genes marcadores de características diagnósticas, como por ejemplo aquellos que codifican para las enzimas de la biosíntesis de las toxinas (Furukawa, et al., 2006). Así, amplificando estos genes se puede inferir la abundancia de células con potencial tóxico en una muestra, de manera altamente específica.

El objetivo principal de este proyecto fue desarrollar herramientas de detección temprana y monitoreo de cianobacterias potencialmente tóxicas. A nivel de los organismos y comunidades, se implementó una herramienta de monitoreo agrupando a los organismos en grupos funcionales (Kruk, et al., 2010). A nivel genético y molecular, se puso a punto una metodología para determinar la abundancia de cianobacterias productoras de microcistinas basada en PCR cuantitativo en tiempo real (qPCR). Asimismo, se cuantificó la microcistina-LR por HPLC mediante cromatografía líquida con detector arreglo de diodo (Lawton, et al., 1994). La aproximación funcional permite resumir la información de muchas especies e hipotetizar sobre sus respuestas a los cambios ambientales. La aproximación genética aporta información sobre la potencialidad de producir toxinas. Ambas son herramientas innovadoras pero fáciles de aplicar, rápidas y que permiten el diagnóstico de situación antes del desarrollo de las floraciones. Asimismo, una estrategia sugerida como adecuada para el monitoreo y gestión de floraciones es el uso de «árboles de decisión» con valores críticos ordenados en distintos niveles de alerta y distintos riesgos de exposición (Chorus y Bartram, 1999; Bonilla, 2009; Rodríguez-Gallego, 2010). En este trabajo se combinaron ambas aproximaciones en un protocolo de monitoreo y un sistema de alerta basado en las nuevas herramientas diseñadas.

Se utilizó un amplio gradiente ambiental y temporal en el Río Uruguay y Río de la Plata para evaluar las herramientas en condiciones que favorecen o limitan el desarrollo de floraciones, incluyendo desde abundancias muy altas hasta abundancias indetectables de los organismos que las causan. El muestreo realizado fue uno de los esfuerzos simultáneos más importantes que se han hecho en Uruguay. Conjuntamente con la estimación de una gran variedad de variables abióticas y bióticas, comunitarias y moleculares, representa un importante aporte a la caracterización de los ecosistemas acuáticos 
estudiados, los cuales tienen un gran valor socioeconómico y para la conservación (e.g. Vizziano, et al., 2001; Acha, et al., 2008). Además, la gran variabilidad de las condiciones abióticas y bióticas sustentan la aplicabilidad de las herramientas diseñadas a otros ecosistemas.

\section{Materiales y Métodos}

\section{Muestreo}

Se realizaron seis campañas de muestreo entre el 20 de enero de 2013 y el 30 de marzo de 2014, cubriendo las cuatro estaciones del año. Se tomaron muestras en seis sitios a lo largo del Río Uruguay y Río de la Plata (Tabla 1, Figura 1). En cada uno de estos sitios se midieron variables in situ y se tomaron muestras en dos estaciones correspondientes a aguas abiertas (AA) y costa (CO), excepto en el Embalse de Salto Grande, donde AA y CO correspondieron a los brazos del embalse generados por los ríos Gualeguaycito e Itapebí, respectivamente (Tabla 1 ).

\section{Variables in situ y muestras}

En cada estación de muestreo (12) se midió la intensidad del viento $\left(\mathrm{ms}^{-1}\right)$, la intensidad de la luz con fotoradiómetro ( $\mu \mathrm{mol}$ fotón $\left.\mathrm{m}^{2} \mathrm{seg}^{-1}\right)$ y la temperatura del aire $\left({ }^{\circ} \mathrm{C}\right)$, así como también la profundidad de la columna de agua con ecosonda $(\mathrm{m})$. Utilizando un multiparámetro se registraron en superficie y fondo la temperatura $\left(\mathrm{T},{ }^{\circ} \mathrm{C}\right)$, conductividad $\left(\mathrm{mScm}^{-1}\right)$, oxígeno disuelto $\left(\mathrm{OD}, \mathrm{mgL}^{-1}\right)$, turbidez $(\mathrm{NTU})$ y salinidad del agua. Se registró visualmente la presencia o ausencia de floraciones definidas como manchas verdes y la presencia de colonias de cianobacterias en un volumen

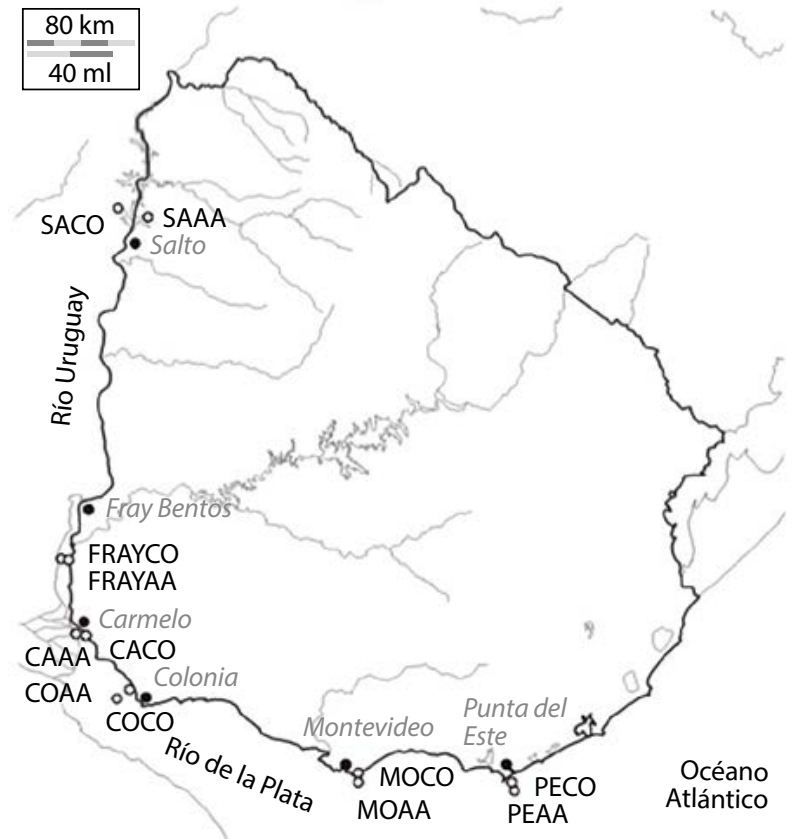

Figura 1. Mapa de los sectores del Río Uruguay y del Río de la Plata que fueron muestreados en este proyecto. Se indican los sitios de muestreo en círculos y refieren a las estaciones correspondientes a costa $(\mathrm{CO})$ y aguas abiertas (AA).

de $20 \mathrm{~L}$ de agua superficial observado en un recipiente de color blanco.

Las muestras de agua para nutrientes, alcalinidad y biológicas se tomaron con una botella Niskin inmediatamente debajo de la superficie del agua (subsuperficialmente). Las

\begin{tabular}{|c|c|c|c|c|c|c|}
\hline Localidad & Estación & Sitio de referencia & Latitud & Longitud & $\begin{array}{c}\text { Distancia } \\
\text { Costa }(\mathbf{k m})\end{array}$ & $\begin{array}{c}\text { Profundidad } \\
(\mathbf{m})\end{array}$ \\
\hline Salto (RU) & AA & Brazo Gualeguaycito & $31^{\circ} 12^{\prime}$ & $57^{\circ} 59^{\prime}$ & 3,7 & 9,6 \\
Salto (RU) & CO & Brazo Itapebi & $31^{\circ} 11^{\prime}$ & $57^{\circ} 52^{\prime}$ & 0,1 & 14,0 \\
Fray Bentos (RU) & AA & Frente a Las Cañas & $33^{\circ} 10^{\prime}$ & $58^{\circ} 23^{\prime}$ & 2,4 & 6,5 \\
Fray Bentos (RU) & CO & Al S de la PNN & $33^{\circ} 10^{\prime}$ & $58^{\circ} 21^{\prime}$ & 0,02 & 1,5 \\
Carmelo (RdlP) & AA & Frente a Carmelo, beril de canal & $34^{\circ} 00^{\prime}$ & $58^{\circ} 22^{\prime}$ & 5,8 & 17,4 \\
Carmelo (RdlP) & CO & Entre Punta Piedras y muelle & $34^{\circ} 00^{\prime}$ & $58^{\circ} 17^{\prime}$ & 0,01 & 2,1 \\
Colonia (RdlP) & AA & Canal del medio NW de isla San & $34^{\circ} 28^{\prime}$ & $57^{\circ} 55^{\prime}$ & 5,9 & 8,0 \\
Colonia (RdlP) & CO & Gabriel & $34^{\circ} 27^{\prime}$ & $57^{\circ} 51^{\prime}$ & 0,01 & 2,0 \\
Montevideo (RdlP) & AA & Al SE de Buen Viaje & $34^{\circ} 58^{\prime}$ & $56^{\circ} 05^{\prime}$ & 7,7 & 7,7 \\
Montevideo (RdlP) & CO & Playa Pocitos & $34^{\circ} 55^{\prime}$ & $56^{\circ} 08^{\prime}$ & 0,03 & 2,3 \\
Punta del Este (RdlP) & AA & W de Punta Britos Isla Gorriti & $34^{\circ} 57^{\prime}$ & $55^{\circ} 02^{\prime}$ & 6,4 & 17,0 \\
Punta del Este (RdlP) & CO & Playa Mansa & $34^{\circ} 55^{\prime}$ & $54^{\circ} 58^{\prime}$ & 0,5 & 7,0 \\
\hline
\end{tabular}

Tabla 1. Nombre, sitio de referencia y coordenadas correspondientes a las estaciones muestreadas. RU= Río Uruguay, $\mathrm{RdlP}=$ Río de la Plata, $\mathrm{AA}=$ aguas abiertas, $\mathrm{CO}=$ costa, $\mathrm{S}=$ sur; $\mathrm{N}=$ norte, $\mathrm{W}=$ oeste, $\mathrm{E}=$ este . 


\begin{tabular}{|c|c|c|c|c|}
\hline Nombre & Secuencia $\left(5^{\prime}{ }^{\prime}{ }^{\prime}\right)$ & Tm $\left({ }^{\circ} \mathrm{C}\right)$ & $\begin{array}{c}\text { Tamaño } \\
\text { esperado }(\mathbf{p b})\end{array}$ & Referencia \\
\hline mcyJMF & TAGCTAAAGCAGGGTTATCG & 51,7 & 242 & Kim et al., 2010 \\
mcyJMR & TCTTACTATTAACCCGCAGC & 51,9 & 242 & Kim et al., 2010 \\
mcyDF2 & GGTTCGCCTGGTCAAAGTAA & 55,2 & 297 & Kaebernick 2000 \\
mcyDR2 & CCTCGCTAAAGAAGGGTTGA & 54,4 & 297 & Kaebernick 2000 \\
mcyBHF03 & AGATTTTAATCCACAAGAAGCTTTATTAGC & 54,4 & 104 & Hautala et al., 2012 \\
mcyBHR0 & CTGTTGCCTCCTAGTTCAAAAAATGACT & 57,5 & 104 & Hautala et al., 2012 \\
mcyE127F & AAGCAAACTGCTCCCGGTATC & 57,6 & 120 & Sipari et al., 2010 \\
mcyE247R & CAATGGGAGCATAACGAGTCAA & 55,1 & 120 & Sipari et al., 2010 \\
\hline
\end{tabular}

Tabla 2. Primers empleados para amplificar fragmentos de genes para la síntesis de microcistinas mediante qPCR en tiempo real.

muestras para toxinas fueron congeladas. Las muestras cuantitativas de fitoplancton fueron fijadas con solución Lugol ( 0,3 a $1 \%$ según concentración de la muestra; Kruk, et al., 2009). Se realizaron también muestreos cualitativos con red de arrastre con una malla de $25 \mu \mathrm{m}$ de poro; estas muestras fueron fijadas con formol al $4 \%$ y guardadas frescas. Para la colecta de fitoplancton de gran tamaño se realizaron arrastres con red cónica de $115 \mu \mathrm{m}$ de malla; estas muestras fueron fijadas con formol $4 \%$ neutralizado y en ellas se registró la presencia de colonias de cianobacterias a simple vista.

\section{Fitoplancton: clorofila-a, composición, abundancia y biovolumen}

Se determinó la concentración de clorofila-a $\left(\mathrm{mg} \mathrm{L}^{-1}\right)$ por triplicado. Para ello se filtraron volúmenes entre 50 y $200 \mathrm{~mL}$ de agua por filtros Whatman GF/F (tamaño de poro nominal ca. $0.7 \mu \mathrm{m})$ que se conservaron a $-20^{\circ} \mathrm{C}$. La extracción se realizó en etanol $95 \%$ en oscuridad por 24 hs a $4^{\circ} \mathrm{C}$, según Jespersen y Christoffersen (1987).

La identificación taxonómica de fitoplancton, a partir de las muestras de arrastre con red, se realizó con microscopio óptico invertido Olympus CKX41 con una magnificación de 1000X. Los organismos de fitoplancton de botella fueron contabilizados y medidos en microscopio invertido Olympus IX81, el cual tiene integrada una cámara CCD de alta velocidad marca Olympus DP71, utilizando el software Cell F para procesar las fotografías. Se utilizaron cámaras Utermöhl (5, $10,15 \mathrm{~mL}$ ) de acuerdo a la concentración de la muestra. Se realizaron conteos por bandas hasta alcanzar 100 organismos de la especie más abundante o 400 organismos en total. Se midieron todos los organismos observados durante el conteo y se realizaron los cálculos de dimensión lineal máxima $(\mathrm{MLD}, \mu \mathrm{m})$ volumen $\left(\mathrm{V}, \mu \mathrm{m}^{3}\right)$ y superficie $\left(\mu \mathrm{m}^{2}\right)$ individual utilizando las aproximaciones geométricas más adecuadas (Hillebrand, et al., 1999). El biovolumen $\left(\mathrm{mm}^{3} \mathrm{~L}^{-1}\right)$ se calculó multiplicando el volumen individual de los organismos por su abundancia. De acuerdo con sus rasgos morfológicos los organismos fueron clasificados en GFBM según Kruk et al. (2010) y el algoritmo desarrollado en el software libre R y disponible en Kruk y Segura (2012). Las especies fueron además clasificadas en las principales clases taxonómicas (i.e. cianobacterias).

\section{Extracción de ADN}

El método empleado para la puesta a punto del método se basó en el descrito por Zhou et al. (1996). Para ello, 250-300 mL de agua se filtraron a través de filtros de membrana de celulosa de $0.2 \mu \mathrm{m}$ de tamaño de poro. Los filtros se almacenaron en placas de Petri estériles a $-20{ }^{\circ} \mathrm{C}$ hasta su empleo para extracción de ADN. Una vez extraído el ADN y confirmada su calidad por espectrofotometría, se almacenó a $-20^{\circ} \mathrm{C}$ hasta su empleo en el qPCR. Los parámetros determinados para luego cuantificar el número de copias fueron el volumen filtrado de muestra y la cantidad total y concentración del ADN obtenido por muestra.

\section{PCR cuantitativo en tiempo real (qPCR)}

El qPCR se ajustó utilizando primers específicos para varios genes del cluster que codifica para la síntesis de microcistinas (mcy), los cuales se obtuvieron de la literatura (Tabla 2). Para las reacciones se usó el kit Power SYBR Green PCR (Invitrogen) con un volumen final de reacción de $20 \mu \mathrm{l}: 9,5 \mu \mathrm{lde}$ agua, $0,5 \mu \mathrm{l}$ de BSA (30mg ml-1), 7,76 $\mu$ de mix (Power SYBR Green PCR), $0,12 \mu \mathrm{l}$ de cada primer $(50 \mu \mathrm{M})$ y $2 \mu \mathrm{l}$ de ADN de la muestra. El termociclador utilizado para los ensayos de qPCR fue TouchTM Real-Time PCR Detection System (BIO $\mathrm{RAD})$ y las condiciones de ciclado fueron $2 \mathrm{~min}$ a $50^{\circ} \mathrm{C}, 15$ min a $95^{\circ} \mathrm{C}$ y 40 ciclos de 15 seg a $94^{\circ} \mathrm{C}, 30$ seg a $60^{\circ} \mathrm{C}$ y 30 seg a $72^{\circ} \mathrm{C}$. Al final se realizó la curva de melting desde 65 ${ }^{\circ} \mathrm{C}$ a $95^{\circ} \mathrm{C}$, en incrementos de $1^{\circ} \mathrm{C}$ cada 4 seg para confirmar la especificidad del fragmento amplificado.

\section{Curva de calibración y cuantificación del número de copias génicas}

La eficiencia de amplificación de los genes fue determinada empleando vectores (plásmidos) que contienen los fragmentos génicos clonados. Para cuantificar el número de copias de cada gen en las muestras se realizaron diluciones seriadas de -10 a -100000 de los genes clonados, se realizó el ajuste de la curva 
y se determinó el número de copias. Una vez conocido el número de copias génicas que contenía cada reacción de PCR, se calculó el número original de copias en la muestra (basados en el volumen filtrado y el rendimiento de ADN obtenido).

\section{HPLC microcistinas}

La microcistina-LR fue cuantificada por HPLC mediante cromatografía líquida con detector arreglo de diodo PEC. AGROPEC.071, basado en la Norma ISO 20179 (International Organization for Standarization, 2005) y Lawton et al. (1994).

\section{Análisis de nutrientes}

El amonio $\left(\mathrm{NH}_{4}{ }^{+}\right)$se midió por medio del método de inyección en flujo, basado en QuikChem Method 10-107-06-2-P (modificado) y por el método electrométrico basado en la norma estadounidense Standard Methods: 4500 NH3-D. El nitrógeno total se estimó por combustión y oxidación a dióxido nitroso y posterior detección por quimioluminiscencia, descrito por la norma ISO/TR 11905-2 (International Organization for Standarization, 1997). El fósforo total (PT) también se analizó utilizando FIA, pero según el método del fabricante del equipo Lachat, QuikChem Method 31-115-01-3-D (Lachat Instruments, 2009). Los silicatos fueron evaluados por medio del método de determinación espectrofotométrico del molibdosilicato, siguiendo la norma estadounidense Standard Methods: 4500-SiO2 C.

\section{Análisis de datos}

Las relaciones bivariadas se evaluaron mediante el coeficiente de correlación de Spearman, indicado como rs en el texto. Se utilizaron pruebas no paramétricas (e.g. Kruskal-Wallis, H) para detectar diferencias en los indicadores tradicionales y desarrollados en este trabajo frente a la presencia o ausencia de floraciones definidas como manchas verdes y frente a la presencia de algas verde-azuladas en el copo de la red de malla de $115 \mu \mathrm{m}$ arrastrada por $\sim 2$ minutos. Las técnicas no paramétricas fueron aplicadas porque varias variables no tuvieron distribución normal y fueron heterocedásticas, por lo que no fue posible cumplir con los supuestos de las técnicas paramétricas. Se utilizó un modelo de regresión lineal simple para evaluar la relación entre la temperatura del agua y del aire. Para analizar la relación entre las variables ambientales y las variables biológicas, incluyendo el biovolumen de los grupos III, V, VI, VII y otros (Gotros), el biovolumen de cianobacterias total (Ciano), la concentración máxima de genes $m c y$ (mcy_max) y la concentración de clorofila-a (Cloa), se utilizaron análisis de correspondencia canónica. Se realizó un análisis de correspondencia con remoción de tendencias (DCA) para seleccionar el tipo de análisis más adecuado en base a la longitud del gradiente de cambio de los grupos. Como la longitud del gradiente fue 1,60 unidades de desvío estándar se realizó un análisis de correspondencia canónico (CCA) (Ter Braak y Smilauer, 1998). Las variables abióticas incluidas fueron todas las formas de nutrientes, intensidad del viento, temperatura, turbidez, salinidad, luz en el aire, alcalinidad y conductividad. La matriz abiótica fue centrada y estandarizada, mientras que las variables biológicas fueron logaritmizadas $\left(\log _{10}(x+1)\right)$. La significancia de los análisis de ordenación se determinó mediante la prueba de Montecarlo, utilizando 499 permutaciones. Se evaluó la importancia de cada variable con un procedimiento de selección hacia adelante (CCA forward) para incluir aquellas que no fueran redundantes con las variables ya introducidas en el modelo; se confirmaron estos resultados utilizando el factor de inflación de varianza (VIF). Todos los análisis fueron realizados con el programa libre R versión 3.1.3. (R Core Team, 2013); para los análisis de ordenación se utilizó el paquete Vegan.

\section{Resultados}

\section{Caracterización ambiental}

Se observaron marcados gradientes en el tiempo y en el espacio. La profundidad varió entre 1 y 17 metros (Tabla 1). Los sitios más profundos correspondieron al embalse de Salto y a aguas abiertas en Punta del Este. Las estaciones costeras fueron siempre las más someras, excepto en el caso de Salto, donde no se mantuvo el esquema costa-aguas abiertas.

Las variables meteorológicas y oceanográficas presentaron una marcada estacionalidad, particularmente la temperatura, intensidad de luz e intensidad de viento (Figura 2A-C). La temperatura superficial del agua varió desde 11 a $34^{\circ} \mathrm{C}$ y estuvo linealmente relacionada con la temperatura del aire (Tagua, ${ }^{\circ} \mathrm{C}$ $=4.3+0.69$ Taire, $\mathrm{R}^{2}=0.61$ ). La irradiancia sobre la superficie del agua presentó valores entre 500 y $4000 \mu \mathrm{mol}$ fotón $\mathrm{m}^{2} \mathrm{seg}^{-1}$ al mediodía y no estuvo relacionada con los indicadores de disponibilidad de luz en la columna de agua. El viento varió entre situaciones de calma $\left(0 \mathrm{~ms}^{-1}\right)$ y brisa fresca $\left(9 \mathrm{~ms}^{-1}\right)$. La temperatura e irradiancia tuvieron un comportamiento similar con mayores valores en los meses de verano. La mayor intensidad del viento se observó en invierno, y tuvo una relación negativa con la temperatura ( $\mathrm{rs}=-0.40, \mathrm{p}<0.05)$.

Los cambios en la salinidad y turbidez fueron marcados en el gradiente espacial (Figura 2D-F). La salinidad fue 0 en las estaciones correspondientes al Río Uruguay y en la parte interior del Río de la Plata (Salto, Fray Bentos, Carmelo y Colonia), tomando valores de 33 en la zona estuarina media y externa (Montevideo y Punta del Este). Montevideo presentó la mayor variación estacional de salinidad ( $\operatorname{rango}=7-33)$. La turbidez tuvo mayores valores en Carmelo y Colonia. Además de los cambios estacionales en la temperatura del agua, esta variable mostró un patrón espacial con una tendencia a valores mayores en Salto y menores en Punta del Este.

El fósforo total tuvo mayores valores en Montevideo y Colonia (Figura 3). La concentración de amonio fue mayor en Salto y Montevideo, donde también se observó la mayor variabilidad (Figura 3). El sílice tuvo una media de 14,3 $\mathrm{mg} \mathrm{L}^{-1}$ y presentó una tendencia a disminuir espacialmente desde Salto hasta Punta del Este (Tabla 3). El fosfato varió entre indetectable y $69 \mu \mathrm{gL}^{-1}$, con mayores concentraciones en Montevideo (Tabla 3). El nitrato tuvo un valor medio de $1,45 \mathrm{mgL}^{-1}$ y sus mayores valores se observaron en Fray Bentos (Tabla 3).

\section{Estimadores globales de fitoplancton e indicadores de floraciones}

Se observaron floraciones en la estación de aguas abiertas de Salto en verano e invierno, incluyendo enero, marzo y junio de 2013, así como en la estación costa de Salto en marzo de 2014. Además de Salto, solo se observó un evento de floración en Colonia en marzo de 2013. La presencia de colonias 
A

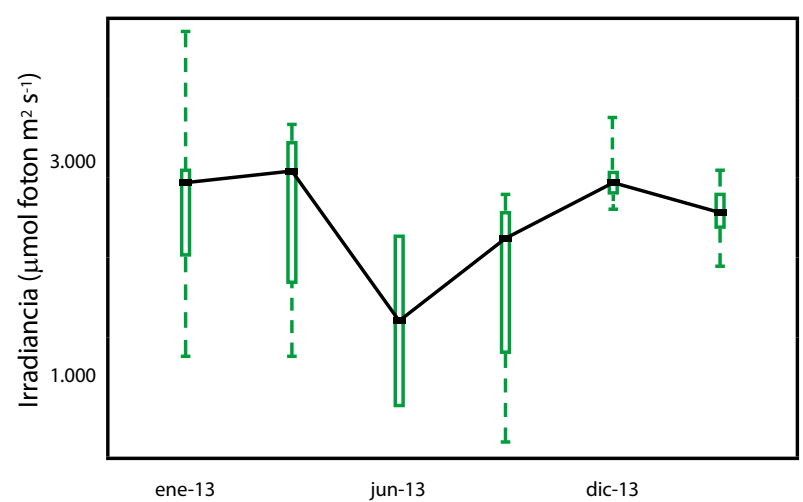

B

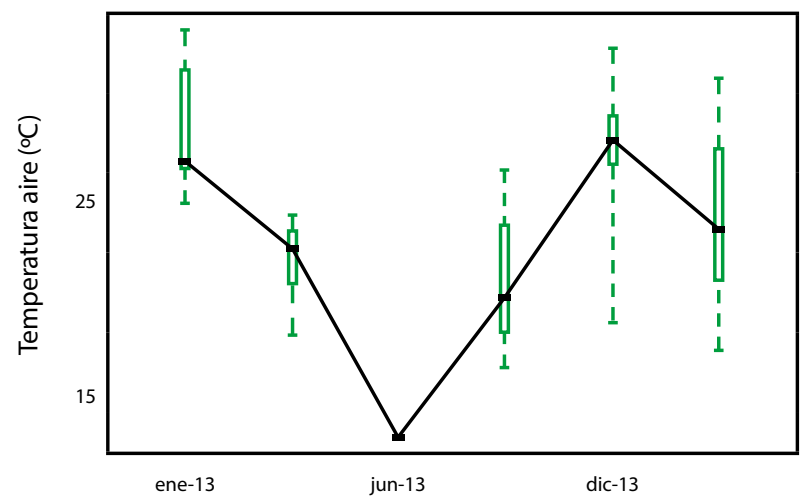

C

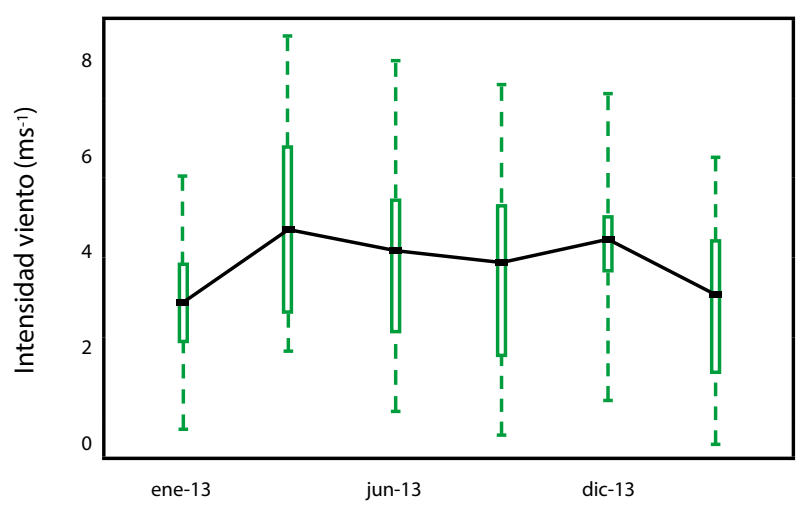

D

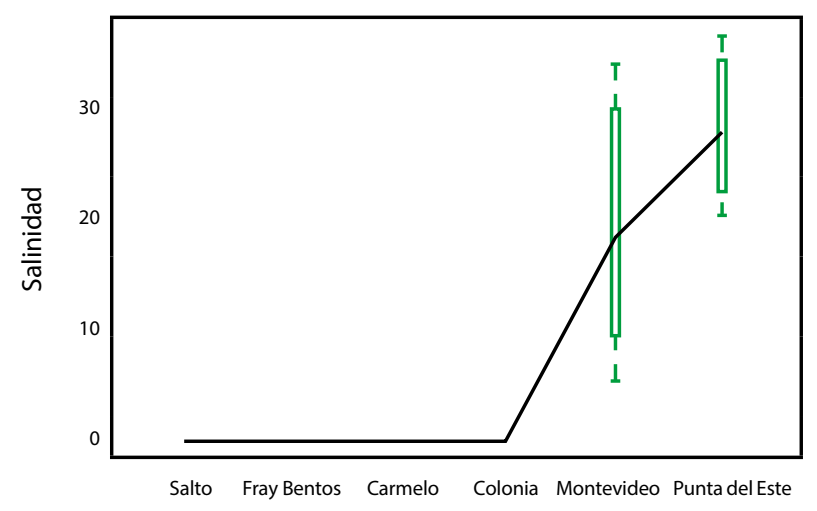

E
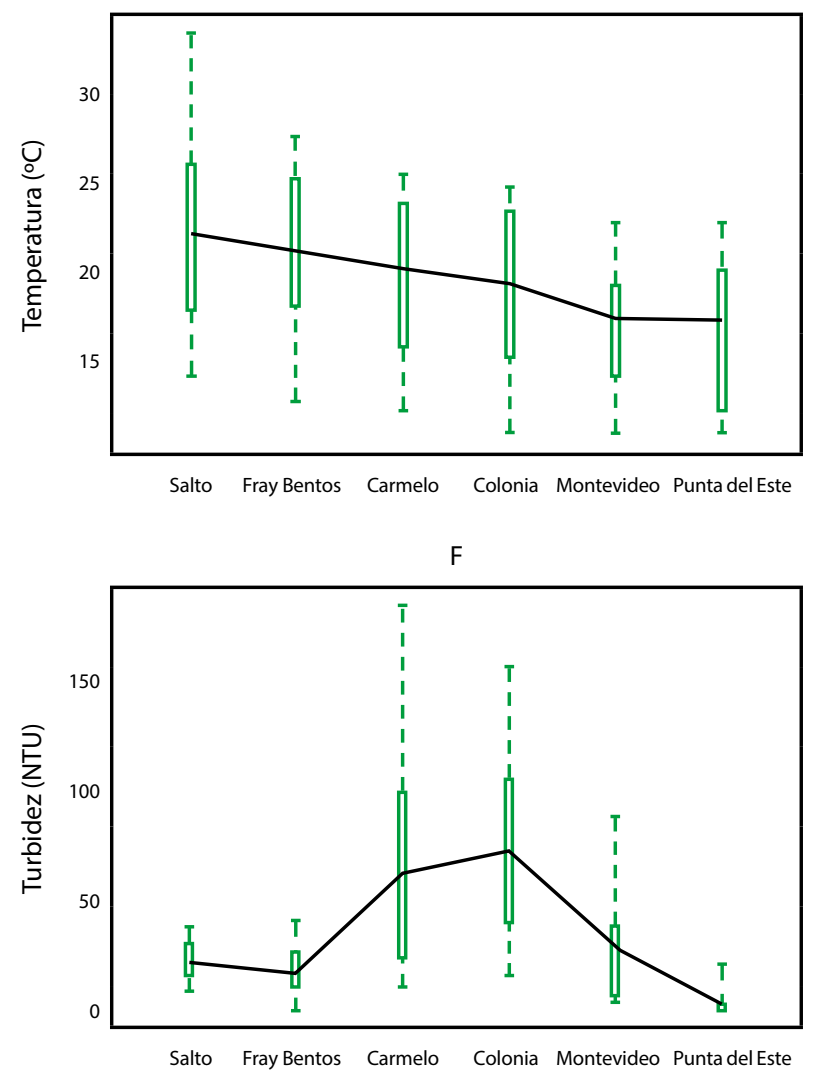

Figura 2. Variabilidad temporal (A-C) y espacial (D-F) de la irradiancia, temperatura, intensidad del viento y turbidez en el Río de la Plata en el período de estudio y para los seis sitios muestreados. Se muestran las medianas y los rangos intercuartiles.

formadoras de floraciones ocurrió en todo el gradiente espacial, salvo en la estación aguas abiertas de Punta del Este. Estas colonias aparecieron en la mayoría de las estaciones en gran parte de las fechas de muestreos y correspondieron en su gran mayoría a organismos de gran tamaño del complejo Microcystis aeruginosa (CMA), los cuales forman parte del GFBM VII que se detalla más adelante.

La concentración de clorofila-a por extracción fue mayor en Salto y Punta del Este, con valores bajos en la zona intermedia del gradiente. El biovolumen total de fitoplancton siguió un patrón similar con una media de $65 \mathrm{~mm}^{3} \mathrm{~L}^{-1}$ (Tabla 3), correlacionado con la clorofila-a $(r s=0,5, p<0,05)$. En cambio, el biovolumen de cianobacterias fue mayor en Salto $\left(2174 \mathrm{~mm}^{3} \mathrm{~L}-1\right)$ y disminuyó hacia Montevideo y Punta del Este, donde fue indetectable en varias ocasiones (Tabla 3), sin estar significativamente relacionado con la concentración de clorofila-a.

\section{Composición específica y grupos funcionales basados en morfología}

Durante el estudio se identificaron un total de 221 especies y se registró la presencia de los 7 GFBM definidos (lista disponible 
A

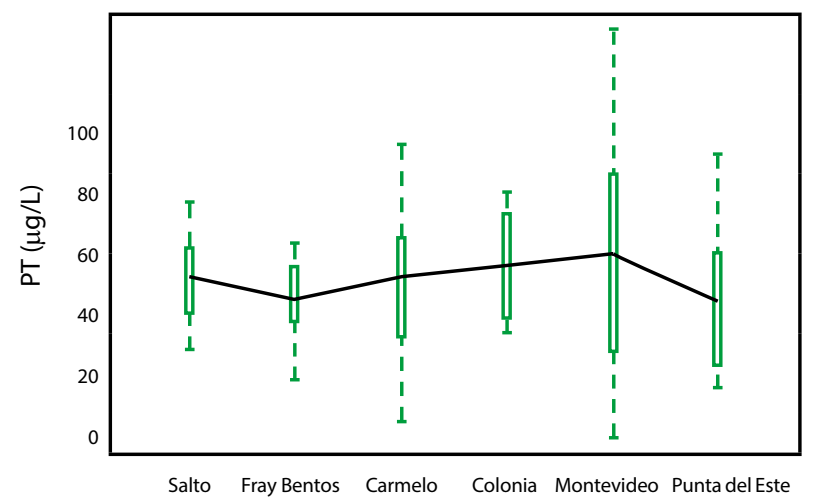

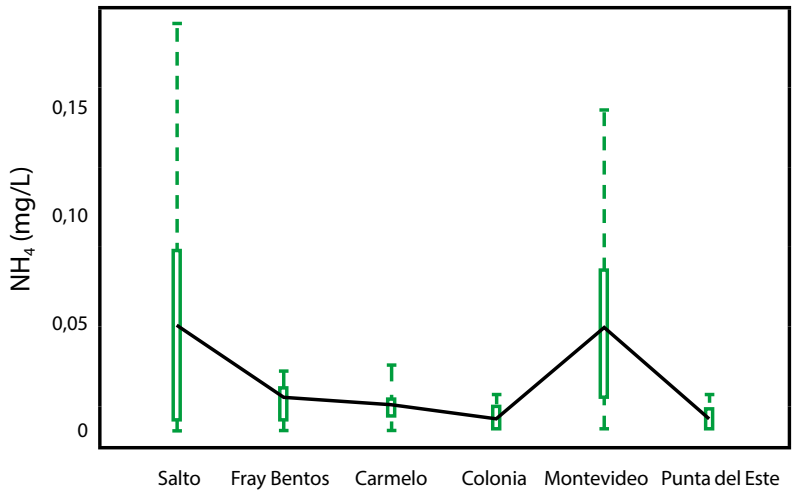

C

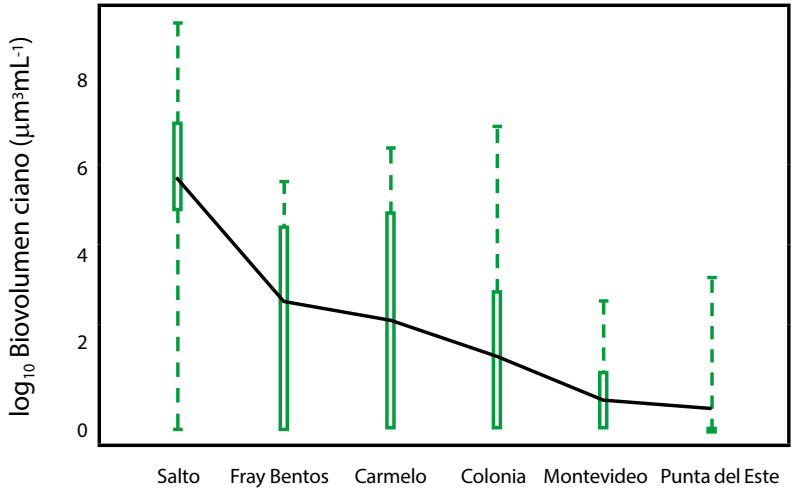

Figura 3. Variación espacial de la concentración de fósforo total $(\mathrm{PT})$, amonio $\left(\mathrm{NH}_{4}\right)$ y biovolumen total de cianobacterias.

\begin{tabular}{|c|c|c|c|c|c|c|}
\hline Sitio & $\begin{array}{l}\text { BV total } \\
\left(\mathrm{mm}^{3} \mathrm{~L}^{-1}\right)\end{array}$ & $\underset{\left(\mathrm{mm}^{3} \mathrm{~L}^{-1}\right)}{\text { cianobyateria }}$ & $\begin{array}{c}\text { Microcistina- } \\
\text { LR } \\
\left(\mathrm{mgL}^{-1}\right)\end{array}$ & $\begin{array}{c}\text { PRS } \\
\left(\mu \mathrm{gL}^{-1}\right)\end{array}$ & $\underset{\left(\mathrm{mgL}^{-1}\right)}{\mathrm{NO}_{3}}$ & $\underset{\left(\mathrm{mgL}^{-1}\right)}{\mathrm{SiO}_{2}}$ \\
\hline \multirow[t]{2}{*}{ Salto } & 361,4 & 457 & 7,07 & 19,9 & 1,8 & 14,4 \\
\hline & $0,2-2188$ & ind-2175 & $0,4-15$ & ind $-53,0$ & $0,4-3,6$ & $12,3-16,6$ \\
\hline \multirow[t]{2}{*}{ Fray Bentos } & 0,5 & 0,06 & ind & 19,9 & 2,1 & 16,2 \\
\hline & $0,1-3,4$ & ind $-0,49$ & - & Ind-59,0 & $0,7-3,8$ & $13,0-25,4$ \\
\hline \multirow[t]{2}{*}{ Carmelo } & 1,4 & 0,35 & ind & 27.7 & 1,8 & 14,2 \\
\hline & Ind-3,8 & ind $-2,90$ & - & Ind-64,0 & $1,1-3,3$ & $11,9-16,6$ \\
\hline \multirow[t]{2}{*}{ Colonia } & 4,7 & 0,8 & 0,24 & 31,4 & 1,7 & 14,3 \\
\hline & Ind- 42,6 & ind-9,11 & ind- 0,34 & Ind- 67,0 & $1,4-2,5$ & $12,4-16,1$ \\
\hline \multirow[t]{2}{*}{ Montevideo } & 2,35 & $1,40 \mathrm{E}-004$ & ind & 23,8 & 0,6 & 6,14 \\
\hline & $0,1-6,7$ & ind $-8,5$ E- 4 & - & $3-69$ & $0,4-1,5$ & $2,20-11,9$ \\
\hline \multirow[t]{2}{*}{$\begin{array}{l}\text { Punta del } \\
\text { Este }\end{array}$} & 19,8 & $2,82 \mathrm{E}-04$ & ind & 21,6 & 0,4 & 4,71 \\
\hline & $0,6-141,4$ & ind $-0,0029$ & - & Ind-67,6 & $0,4-0,5$ & $0,64-11,1$ \\
\hline
\end{tabular}

Tabla 3. Valores medios y rangos de variables biológicas y nutrientes disueltos en cada sitio de muestreo. $\mathrm{BV}=$ biovolumen, $\mathrm{PSR}=$ fósforo reactivo soluble, $\mathrm{NO}_{3}=$ nitrato, $\mathrm{SiO}_{2}=$ silice, Ind= indetectable. 
solicitándola al autor de contacto de este artículo). De estos, los grupos V (flagelados de tamaño medio) y VI (organismos con pared de sílice) fueron los que mayor aporte hicieron al biovolumen total de la comunidad de fitoplancton ( $r s=0,70 ; p<0,05$ y rs $=0,51 ; p<0,05$, respectivamente). El GFBM VII (colonias de gran tamaño con mucílago) fue el grupo que incluye cianobacterias que alcanzó mayores biomasas (media $=57,2 \mathrm{~mm}^{3} \mathrm{~L}^{-1}$; rango $=$ ind $-2173 \mathrm{~mm}^{3} \mathrm{~L}^{-1}$ ) siendo dominante en Salto (media $=454 \mathrm{~mm}^{3} \mathrm{~L}^{-1}$ ) y disminuyendo hacia Punta del Este (media $=$ $\left.1,07 \mathrm{E}-3 \mathrm{~mm}^{3} \mathrm{~L}^{-1}\right)$. Asimismo, fue el grupo que aportó en mayor proporción al biovolumen total de cianobacterias ( $\mathrm{rs}=0,84, \mathrm{p}<$ 0,05). Dentro del grupo VII se identificaron 14 especies en su mayoría integrantes del Complejo Microcystis aeruginosa (CMA).

\section{Microcistinas}

La concentración de microcistina-LR se encontró en general bajo el límite de detección, salvo en cinco ocasiones. En Salto (estación aguas abiertas) alcanzó su máximo valor en enero de 2013 con $15 \mu \mathrm{gL}^{-1}$ (Tabla 3). Fue nuevamente detectada en marzo del mismo año en Salto y Colonia, pero con menores valores (Tabla 3).

\section{Cuantificación de genes para la síntesis de microcistinas}

Se puso a punto la metodología basada en qPCR que permite determinar rápidamente la presencia y abundancia de cianobacterias productoras de microcistina en muestras de agua. Además, se determinó la concentración de dichas toxinas por HPLC. Se detectaron genes $m c y$ en virtualmente todas las fechas y estaciones de muestreo (media $=1,70 \mathrm{E}+04 \mathrm{co}-$ pias $\mathrm{mL}^{-1}$, rango $=$ ind $-8,33 \mathrm{E}+05$ copias $\left.\mathrm{mL}^{-1}\right)$. Las mayores abundancias se registraron en la zona de Salto Grande y Fray Bentos, disminuyendo significativamente hacia las estaciones estuarinas (Montevideo y Punta del Este).

Se utilizó la relación entre la concentración total de genes $m c y$ y el biovolumen del CMA como indicador de la proporción de organismos con el potencial de producir toxinas. Esta fue mayor en Salto y disminuyó hacia Punta del Este, aunque allí no llegó a ser 0 (Figura 4). Este indicador fue positivo en un número mucho mayor de casos que la concentración de microcistintas-LR (Figura 4).

\section{Relaciones entre distintos indicadores biológicos y las condiciones ambientales}

Los indicadores simples como la presencia de colonias de CMA observables a simple vista en un recipiente blanco y la presencia de floraciones de cianobacterias como manchas verdes en la superficie del agua, estuvieron positivamente asociadas a los indicadores estimados con metodologías más complejas (Figura 5). En condiciones de presencia de colonias no se observaron diferencias significativas en la concentración de clorofila-a total o de biovolumen total de fitoplancton (Figura $5 \mathrm{~A}$ y B). Sin embargo, sí se detectaron diferencias significativas cuando se analizó el biovolumen del grupo VII en relación a la abundancia de genes $m c y B$ y $m c y E$ (Figura $5 \mathrm{C}, \mathrm{E}$ y F). Cuando hubo colonias se observó una mayor concentración de microcistinas $\left(\mathrm{H}_{(1,72)}=7,319, \mathrm{p}=0,01\right)$. Comparando situaciones de presencia $\mathrm{o}$ ausencia de floraciones se observaron diferencias en todos los indicadores, incluyendo las microcistintas $\left(\mathrm{H}_{(1,72)}\right.$ $=13,76, \mathrm{p}<0,001$ ) (Figura 5G a L).

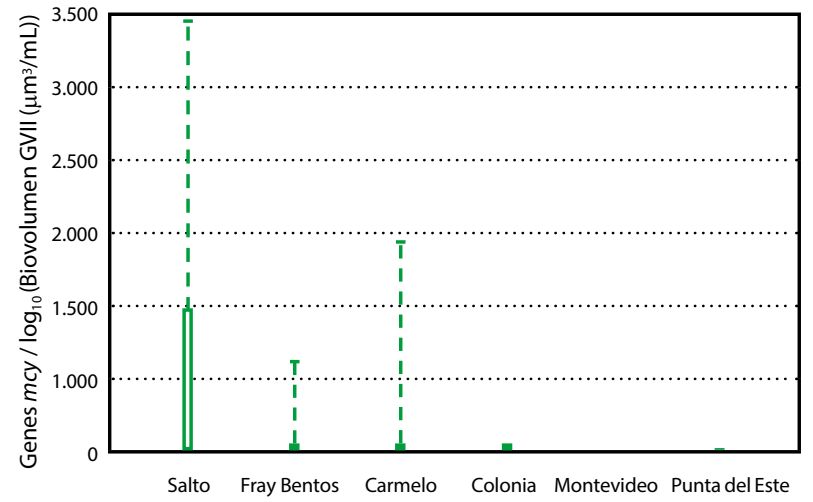

Figura 4. Relación entre la concentración de genes mcy y el biovolumen del complejo Microcystis aeruginosa (CMA) a lo largo del espacio.

Las variables finalmente seleccionadas en el CCA como mejor conjunto explicativo de las variables biológicas fueron: $\mathrm{NO}_{3}, \mathrm{SiO}_{2}$, viento, temperatura, turbidez, salinidad y luz en el aire (Figura 6). De la totalidad de la varianza (inercia) $41 \%$ fue explicada por las variables biológicas condicionadas por las ambientales, mientras que el $59 \%$ fue explicada por las variables biológicas propiamente dichas. $\mathrm{El} \mathrm{R}^{2}$ fue $0,41 \mathrm{y}$ el test de Montecarlo tuvo un $\mathrm{F}=3,52$ con un $\mathrm{p}<0,01$.

Se observó un gradiente de mayores temperatura, turbidez, luz en aire y concentración de nutrientes (representativo de estaciones límnicas) a mayores salinidades e intensidad de viento con menores temperaturas y nutrientes y menos disponibilidad de luz en la columna de agua (representativo de estaciones más marinas) (Figura 7). Los grupos V (flagelados de tamaño medio a grande) y VI (diatomeas) se asociaron a las condiciones marinas, mientras que los grupos VII, III y otros estuvieron asociados a ambientes límnicos. Dentro de las condiciones límnicas el grupo VII, las cianobacterias y la presencia de colonias prefirieron condiciones de mayor concentración de nutrientes y luz incidente, mientras que el grupo III, la presencia de floraciones, otros grupos y la presencia de colonias de CMA en red de zooplancton, junto con la concentración de clorofila-a y la abundancia máxima de genes $m c y$, se asociaron a condiciones intermedias de nutrientes y mayores temperaturas.

\section{Esquema de monitoreo de floraciones tóxicas del CMA}

En base a los resultados previos se propuso un sistema de alerta y monitoreo dinámico en el cual es posible identificar tres grandes etapas: 1) análisis visual del espejo de agua, 2) análisis visual de concentrado de agua in situ y 3 ) análisis de laboratorio con metodologías simples (Figura 7). De forma esquemática, en la etapa 1 se parte del análisis visual del agua, la cual puede presentar floraciones que son evidentes a simple vista y se reconocen como manchas verdes superficiales. Este nivel de alerta debe disparar la generación de medidas precautorias urgentes que varían según los usos del ecosistema. En caso de no ser visible una floración, se continúa con la etapa 2, que incluye desde la colecta de 20 litros de agua en un recipiente de color blanco para identificar visualmente la presencia de colonias, hasta el arrastre de grandes volúmenes de agua (ca. $7000 \mathrm{~L}$ ) con redes de $100 \mu \mathrm{m}$ de malla utilizando embarcación con motor. En la etapa 3 se toman 
A

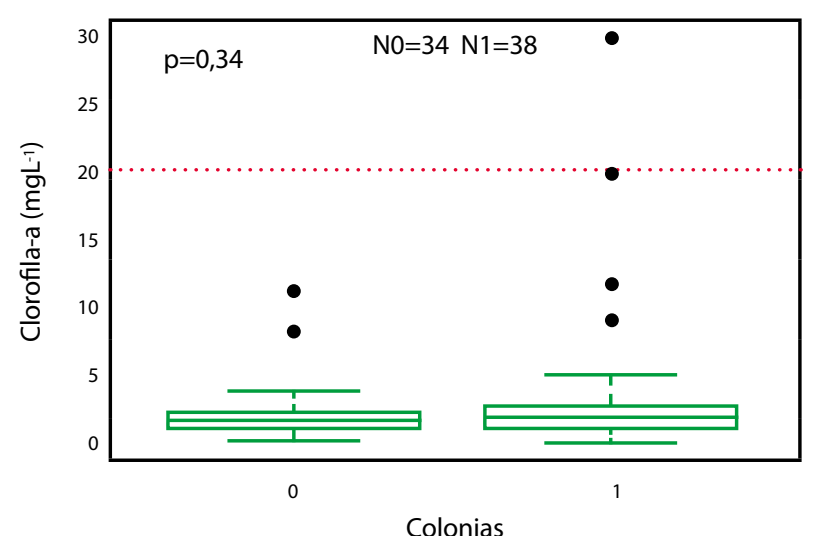

C

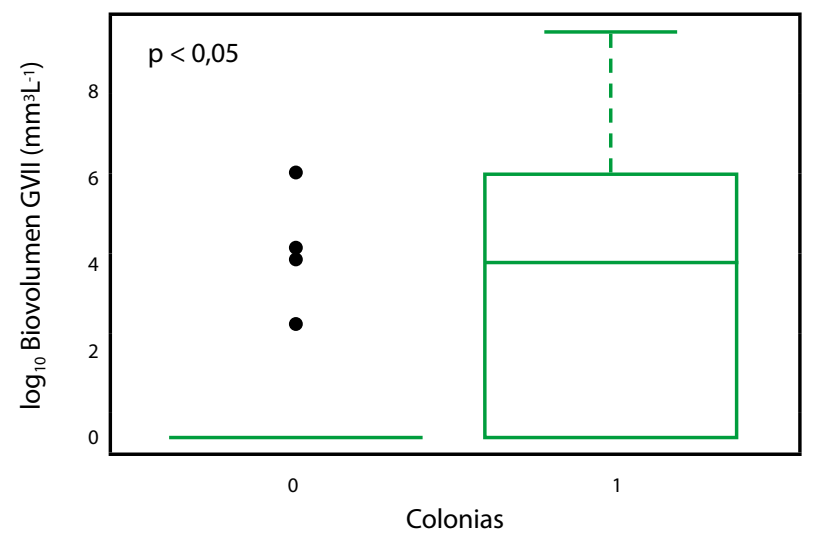

E

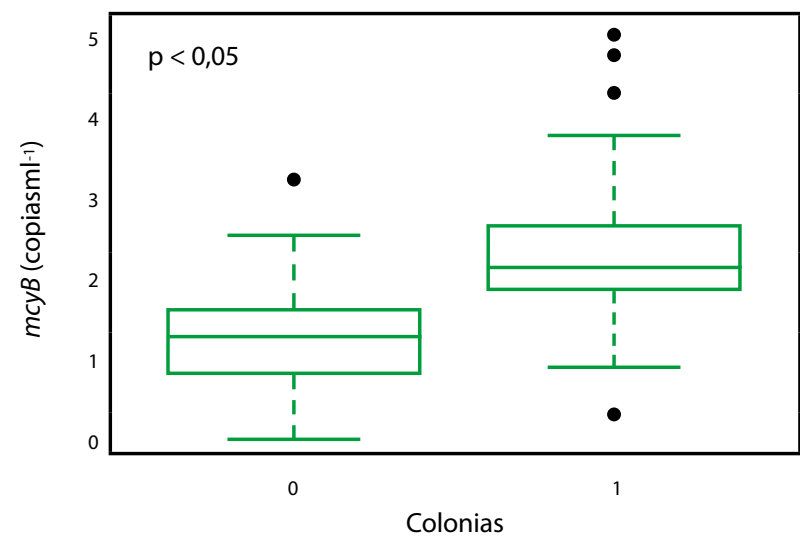

G

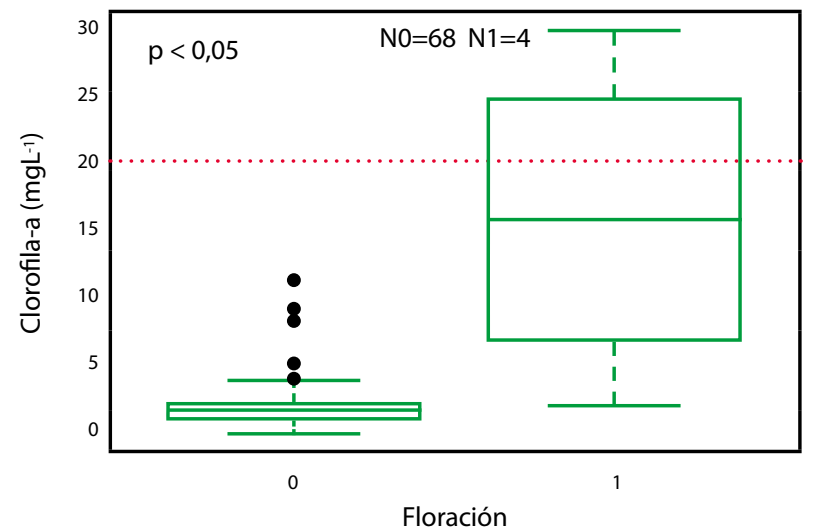

B

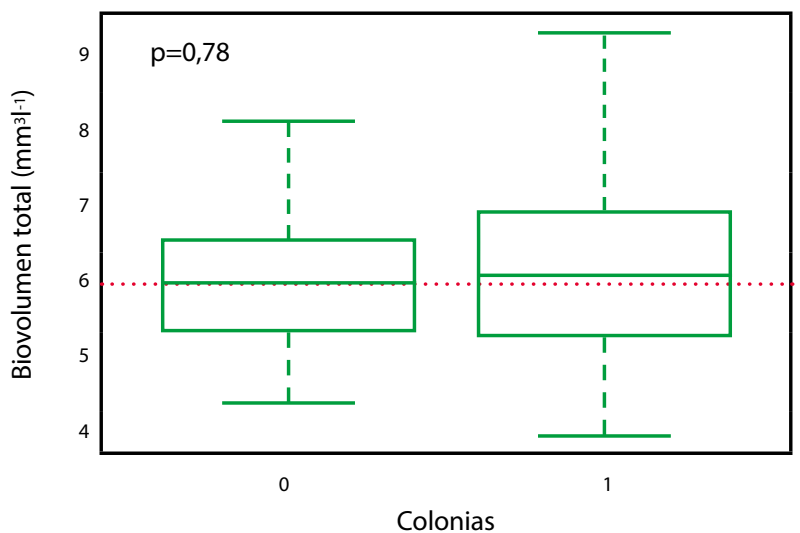

D

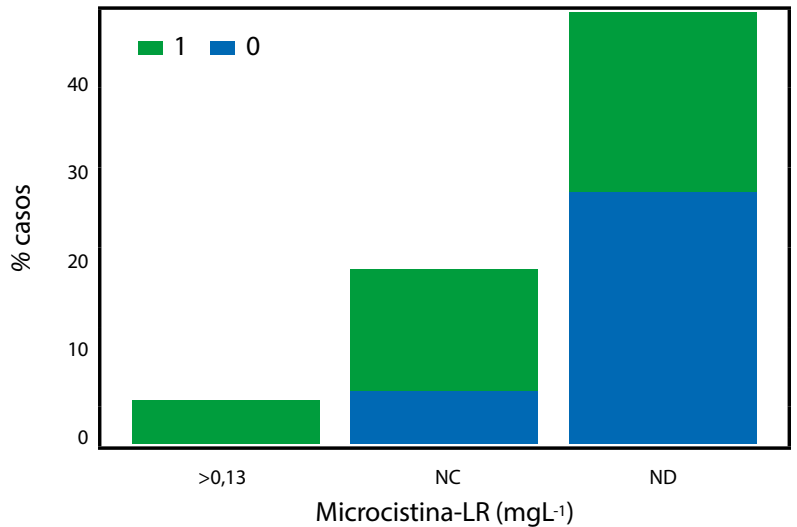

F

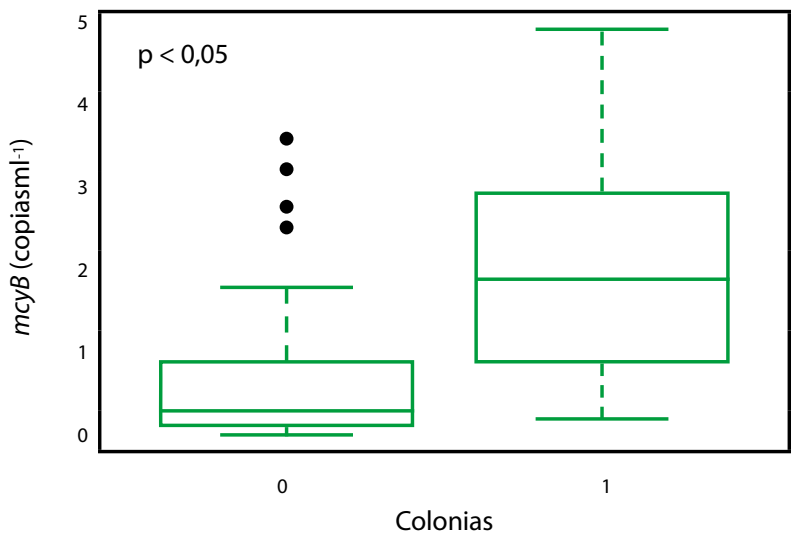

H

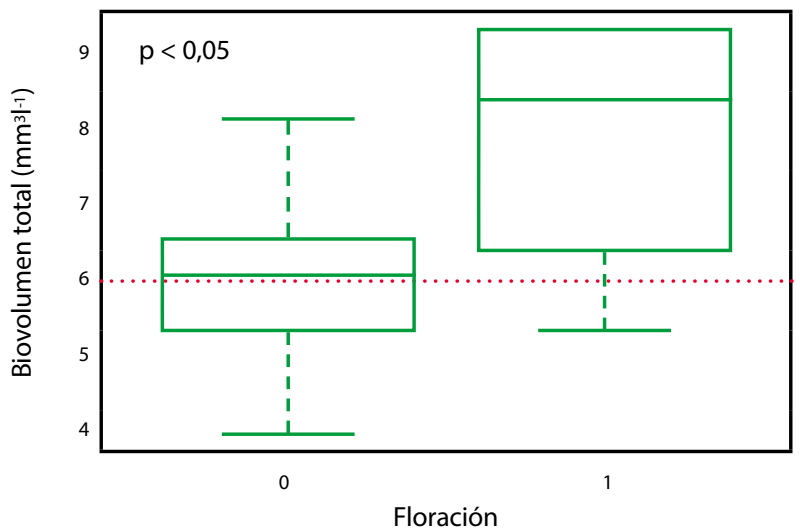




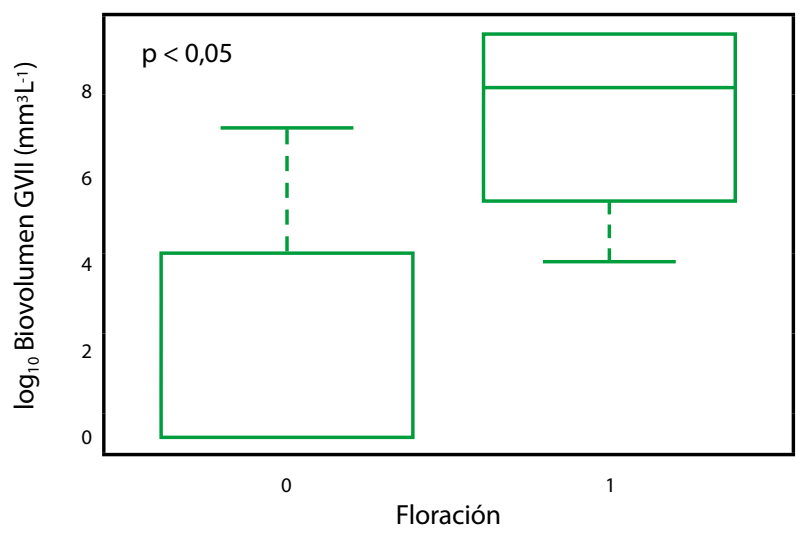

K

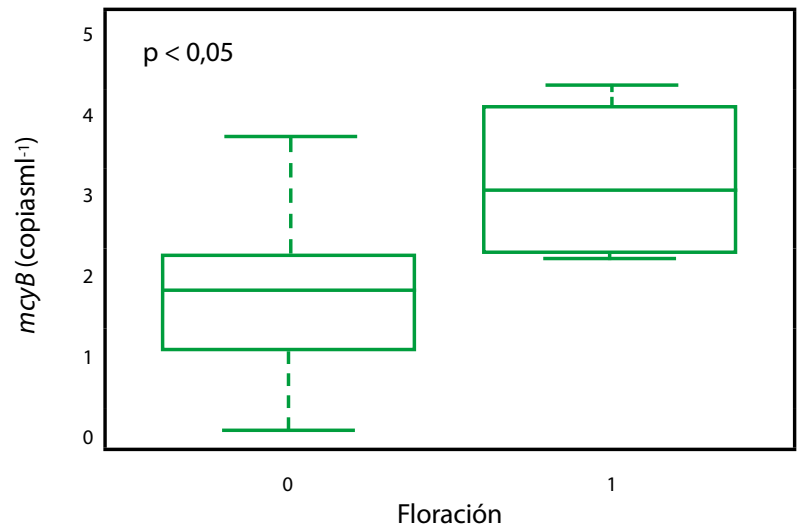

J

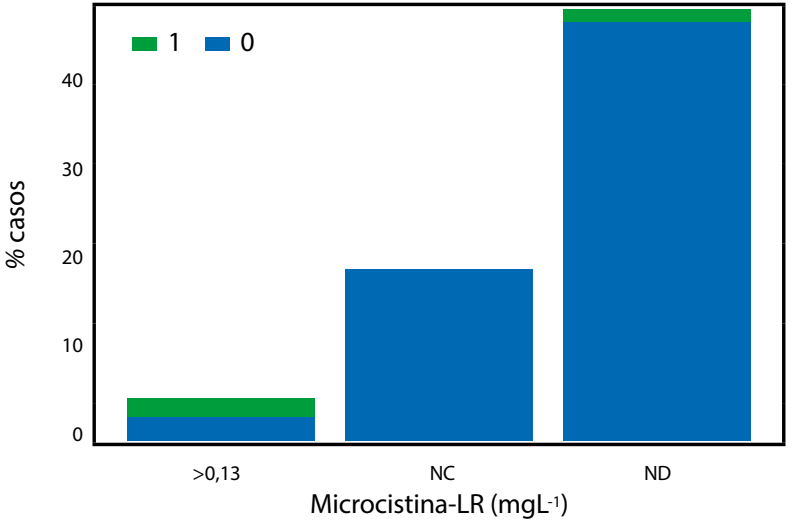

$\mathrm{L}$

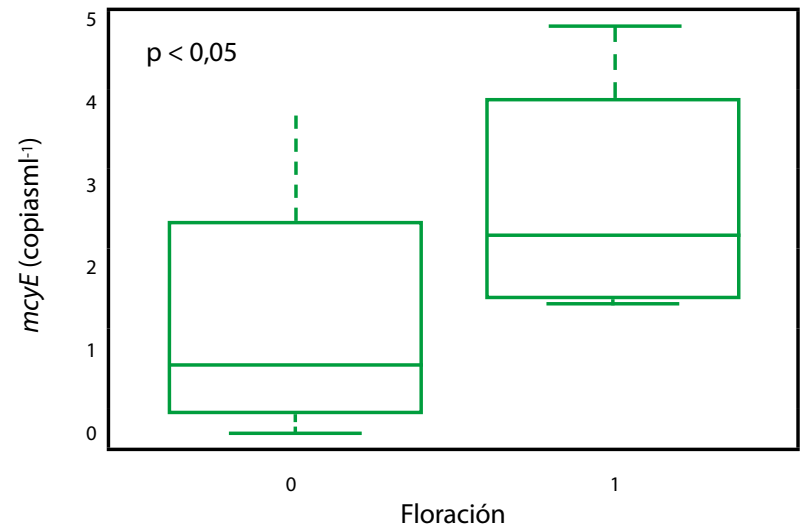

Figura 5. Valores medios y rangos intercuartiles de indicadores tradicionales (clorofila-a, biovolumen total de fitoplancton, concentración de microcistina-LR) y desarrollados en este trabajo (biovolumen del grupo funcional basado en morfología GVII, abundancia de genes $m c y B$ y $E$ ) con indicadores de presencia y abundancia de organismos formadores de floraciones de cianobacterias del complejo Microcystis aeruginosa (CMA). Los paneles de A a F indican los valores de estos indicadores frente a la presencia o no de colonias de CMA en un balde blanco de 20 litros y los paneles $\mathrm{G}$ a L los valores frente a la presencia o no de floraciones identificadas como manchas verdes en la superficie del agua. Las líneas rojas corresponden a niveles guía descritos en Chorus (2012).

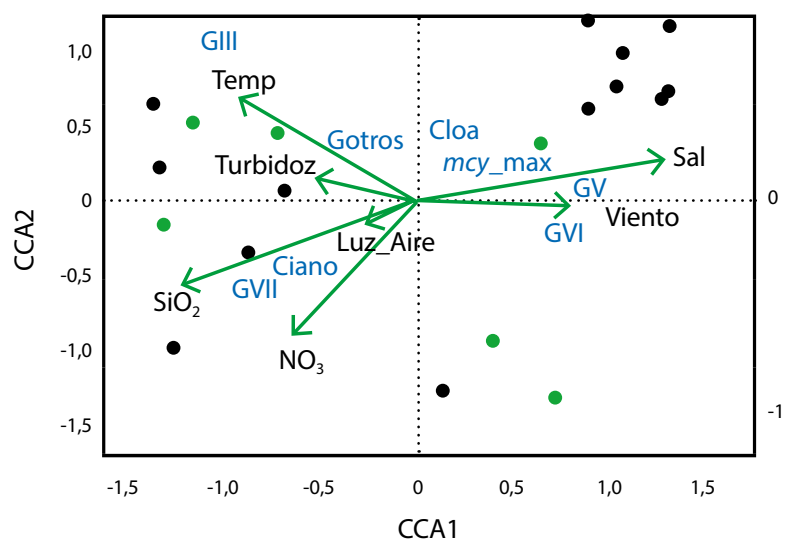

Figura 6. Triplot mostrando los resultados del análisis de correspondencia canónica (CCA), incluyendo los sitios (círculos), las variables biológicas y las variables ambientales (flechas). Se muestran el primer (CCA1) y segundo (CCA2) ejes canónicos. Los círculos que representan los sitios están coloreados de negro y verde, indicando la presencia o no, respectivamente, de colonias de CMA en los arrastres de red de zooplancton. Abreviaciones descritas en Materiales y Métodos. muestras que serán evaluadas en el laboratorio utilizando distintas técnicas, incluyendo análisis al microscopio óptico, evaluación de la presencia de toxinas en el agua (HPLC) y, en el caso de contar con la infraestructura necesaria y cuando el uso previsto del agua así lo amerite (potabilización por ej.), se puede aplicar qPCR en tiempo real para la detección y/o cuantificación de genes involucrados en la síntesis de microcistinas. Así, no solo se tendrá información sobre la presencia de colonias de organismos del CMA, sino también sobre su potencial toxicidad.

\section{Discusión}

Los principales resultados de este trabajo incluyen la puesta a punto de métodos combinando aproximaciones funcionales y moleculares para determinar y monitorear cianobacterias formadoras de floraciones potencialmente tóxicas. Este tipo de herramientas son cada vez más exploradas en estudios de ecología en general (Mc Gill, et al., 2006) y su aplicación con fines técnicos se ha iniciado recientemente (Dittmanna y Börner, 2005; Pearson y Neilan, 2008; Padisák, et al., 2009; Humbert, et al., 2010). Su importancia radica en la 

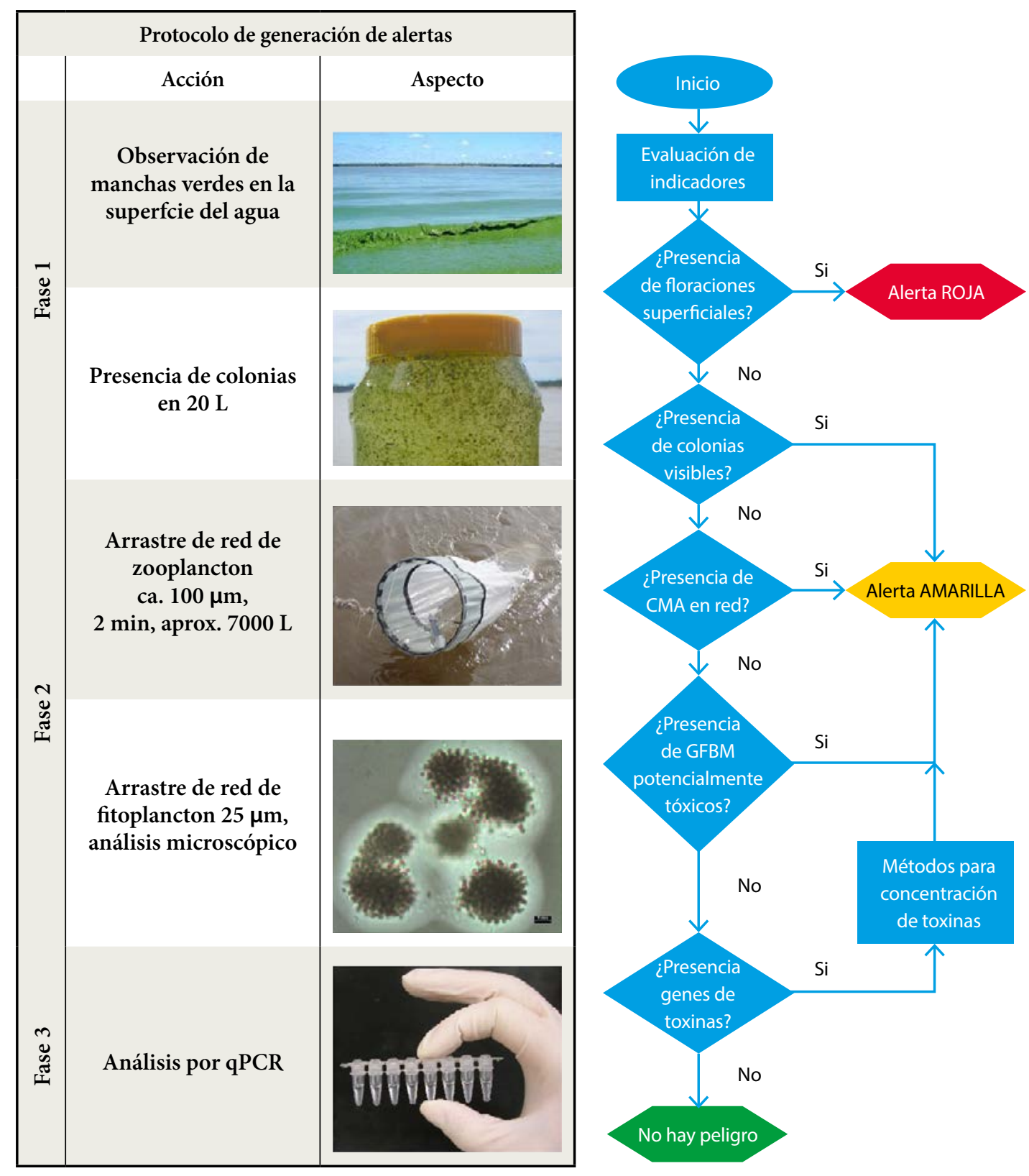

Figura 7. Protocolo de monitoreo y sistema de alerta. CMA=Complejo Microcystis aeruginosa, GFBM = grupos funcionales basados en morfología, qPCR = PCR cuantitativo.

consideración de los distintos niveles de organización y los múltiples factores condicionantes de las comunidades biológicas, resumiendo la información sin perder la necesaria para entender los principales mecanismos ecológicos condicionantes. De esta manera es posible mejorar la gestión de las problemáticas ambientales, incluyendo la predictibilidad de las medidas y cambios adoptados (Mc Gill, et al., 2006; Padisák, et al., 2009; Borics, et al., 2014).

\section{Caracterización ambiental}

Se observaron marcados gradientes espaciales y estacionales en el continuo Río Uruguay - Río de la Plata. Si bien no existen estudios previos que simultáneamente analicen estos dos ecosistemas, nuestros resultados coinciden con estudios realizados independientemente para el Río de la Plata (i.e. Mianzan, et al., 2001; Acha, et al., 2008; Garcia y Bonel, 2014) y algunas zonas del Río Uruguay (i.e. Ferrari, et al., 2011; Saizar, et al., 2011). Las diferencias de turbidez y salinidad marcaron las zonas de influencia dulceacuícola y marina, las cuales estuvieron separadas por los frentes de salinidad y turbidez, como ya se ha señalado en trabajos previos (Framiñan y Brown, 1996; Guerrero, et al., 1997; Acha, et al., 2008; Kruk, et al., 2014). Las variaciones de temperatura e irradiancia se correspondieron con condiciones promedio de los registros históricos (García-Rodríguez, et al., 2013). La relación significativa entre la temperatura del aire y del agua permitiría en futuros trabajos utilizar esta variable como un buen indicador de las condiciones en los ecosistemas. La intensidad del viento fue también determinante de la dinámica espacial local (Sathicq, et al., 2014). 
Cuando se analizaron los nutrientes en el gradiente no se observaron patrones claros, salvo los aumentos asociados a Salto y Montevideo, posiblemente vinculados a la contaminación urbana (Muniz, et al., 2011). De acuerdo a Salas y Martino (1991), y en base a valores medios anuales de fósforo, todos los sitios de muestreo pueden clasificarse entre meso a hiper-eutróficos. La disminución de sílice hacia Punta del Este mostró una disminución de los efectos de la costa y fue lo esperable para una variable conservativa (Calliari, et al., 2005). En cuanto a la calidad de agua asociada a los nutrientes y según los umbrales establecidos en las normativas (Decreto 237/979, Uruguay, 1979), la concentración de fósforo total fue superior a la permitida para aguas de potabilización y estuvo dentro del rango aceptable para aguas de recreación en la mayor parte de los sitios y fechas de estudio. Esto es relevante, ya que indicaría que no hay problemas para los usos recreativos de los cuerpos de agua, pero sí podría haber problemas para toma de agua potable, ya sea en tomas existentes o para el futuro establecimiento de nuevas. Monitoreos realizados previamente en el Río Uruguay ya habían identificaron valores de fósforo por encima de los permitidos en Uruguay (Saizar, et al., 2011). La concentración de amonio alcanzó valores mayores a los límites establecidos en este decreto en Salto y Montevideo.

\section{Estimadores globales de fitoplancton e indicadores de floraciones}

Solo se observaron floraciones de cianobacterias formando manchas en Salto y Colonia. Estas floraciones correspondieron a Microcystis aeruginosa y otras especies y géneros afines agrupados en el Complejo Microcystis aeruginosa (CMA). Estas son muy frecuentes en nuestro país, donde desarrollan importantes floraciones en el verano, tanto en el Río Uruguay como en el Río de la Plata (De León y Yunes, 2001; Kruk y De León, 2002; Vidal y Kruk, 2008; Bonilla, et al., 2011; Ferrari, et al., 2011; Vidal y Britos, 2012). Cabe destacar que uno de los eventos de floraciones con formación de acumulaciones en la superficie del agua ocurrió en junio con temperaturas de $14^{\circ} \mathrm{C}$ en el agua. Esto es especialmente significativo dado que estudios previos indican que estos organismos tienen óptimos de temperatura para el crecimiento cercanos a los $25{ }^{\circ} \mathrm{C}$ (Paerl y Huisman, 2009). A pesar de que por métodos tradicionales (muestreo con botella) la presencia de CMA fue solo registrada hasta Colonia, la utilización de redes que permiten concentrar grandes volúmenes de agua detectó la presencia de organismos formadores de floraciones del CMA en todo el gradiente y la mayor parte del año.

La biomasa de fitoplancton estimada como clorofila-a y biovolumen fue mayor en los extremos del gradiente geográfico (Salto y Punta del Este), en concordancia con estudios previos (Gómez, et al., 2004; Calliari, et al., 2005; O’Farrell, et al., 2007; Acha, et al., 2008). La clorofila-a de acuerdo a Salas y Martino (1991) permitió clasificar a los sitios entre meso a hiper-eutróficos (Salas y Martino, 1991).

El biovolumen de cianobacterias estimado por conteo clásico a partir de muestras de botella fue mucho mayor en Salto e indetectable hacia Punta del Este. Esto coincide con estudios que mostraron muy altas abundancias de cianobacterias en el embalse de Salto Grande, particularmente en el brazo de Gualeguaycito (O’Farrell, et al., 2012). En Salto esta variable sobrepasó los límites recomendados por normativas internacionales para agua de uso recreativo (Chorus, 2012).
Esto se debería a las mayores temperaturas, mayor estabilidad del agua y concentraciones suficientes de nutrientes observadas en el embalse de Salto Grande, como han sugerido otros estudios (Chalar, 2009; O’Farrell, et al., 2012).

La alta clorofila-a y biovolumen de fitoplancton en las estaciones salinas estaría dada por una alta disponibilidad de recursos, luz y nutrientes, pero a diferencia de lo observado en Salto no estaría representada por cianobacterias, sino por diatomeas y flagelados. Esto es concordante con trabajos realizados en el Río de la Plata, donde hay un gradiente en la estructura comunitaria desde zonas de influencia límnica a zonas de influencia marina (Ferrari y Pérez, 2002; Ferrari, 2008; Ferrari, et al., 2011; Kruk, et al., 2014).

\section{Composición específica y grupos funcionales basados en morfología}

De todas las especies observadas y según la literatura (i.e. Chorus, 2012) el 13\% fueron potencialmente tóxicas e incluyeron cianobacterias, dinoflagelados y diatomeas. De las especies potencialmente tóxicas y de acuerdo a la literatura, $27 \%$ fueron potenciales productoras de saxitoxinas, $37 \%$ de microcistinas y $36 \%$ de otras toxinas. En un estudio realizado entre 2006-2009 en el Río Uruguay, un total de 24 taxa fueron identificadas, con los géneros Dolichospermum y Microcystis como las especies más representativas en las floraciones de cianobacterias en el Río Uruguay (Ferrari, et al., 2011).

El GFBM VII fue el grupo que alcanzó mayores biomasas, dominando en Salto y disminuyendo hacia Punta del Este. Esto coincidió con lo encontrado previamente en la misma zona (O'Farrell, et al., 2012). Este grupo incluye colonias mucilaginosas de gran tamaño que controlan su posición en la columna de agua (Reynolds y Walsby, 1975; Reynolds, et al., 2002; Reynolds, 2007; Kruk, et al., 2010). Estos organismos son sensibles a las bajas concentraciones de nutrientes y resistentes a la depredación y el bajo tiempo de residencia (Reynolds, 2002; Kruk, et al., 2010; Kruk, et al., 2012). Pueden alcanzar altas biomasas y formar floraciones superficiales, y son los únicos que presentaron floraciones en el período de estudio. Dentro de las 14 especies observadas de este grupo, siete fueron potencialmente tóxicas y estuvieron principalmente representadas por el CMA, incluyendo al menos seis especies de este grupo. Todas ellas forman grandes colonias con mucílago y aerotopos, se caracterizan además por tener un ciclo de vida conspicuo y colonias que sobreviven al invierno en el sedimento (Reynolds, et al., 1981; Komárek y Komárková, 2003). Otsuka et al. (1999; 2000) basados en secuencias del operon de ficocianina y el espaciador transcripto intergenético (ITS), propusieron la unificación de todas las especies de Microcystis en un único complejo Microcystis aeruginosa (CMA) (Otsuka, et al., 1999; Otsuka, et al., 2000; Bittencourt-Oliveira, 2003). Las especies de este grupo se caracterizan por producir varias toxinas, principalmente microcistinas (MC), de las que potencialmente producen al menos 11 variedades, incluyendo MC-LR. Estudios previos han indicado co-dominancia de especies del GFBM VII con especies el grupo III (filamentos de gran tamaño, alta relación superficie/volumen y aerotopos) (Ferrari, et al., 2011). Sin embargo, en este estudio el biovolumen de este grupo y de especies representativas como Dolichospermum fue relativamente bajo.

El grupo VII se caracteriza por su sensibilidad a la profundidad de mezcla y la disponibilidad de nutrientes 
(Kruk, et al., 2010; Kruk y Segura, 2012), siendo favorecido en ecosistemas de mayor estado trófico, alta residencia del agua y estabilidad de la columna de agua, lo que le permitiría formar floraciones superficiales (Chorus y Bartram, 1999; Kruk y Segura, 2012). Sumado a esto, las mayores temperaturas habrían favorecido las altas biomasas alcanzadas (Paerl y Huisman, 2009; Kruk y Segura, 2012).

\section{Microcistinas y genes $m c y$}

La concentración de microcistina-LR fue en general indetectable, salvo en Salto y Colonia. Por otro lado, los genes $m c y$ estuvieron presentes en todo el gradiente indicando el potencial para el desarrollo de floraciones en todos los sitios estudiados a lo largo del año. Más allá de esto, la salinidad y temperatura aparecerían como vinculadas a la abundancia de poblaciones tóxicas del complejo Microcystis, modulando su abundancia, y en concordancia con las características biológicas de las cianobacterias (Whitton y Potts, 2000; Cabrera, et al., 2013) la salinidad sería un factor clave en el establecimiento de floraciones de cianobacterias, seguida del viento y su efecto en la hidrodinámica.

\section{Ventajas y desventajas de las diferentes metodologías utilizadas}

En este trabajo se utilizaron metodologías tradicionales como la presencia de floraciones, clorofila-a, biovolumen de cianobacterias y la composición de especies, y se desarrollaron herramientas nuevas. Estas últimas incluyeron indicadores simples, como la presencia de CMA en red de arrastre, y complejos, como la estimación de biovolumen de GFBM y abundancia de genes que codifican para microcistinas. Todas estas metodologías tienen sus ventajas y desventajas. La concentración de clorofila-a es un indicador global de amplia utilización, pero no da cuenta de la composición y toxicidad. La composición específica es fundamental para entender los potenciales efectos de las especies, pero su identificación es dificultosa, y la presencia de especies potencialmente tóxicas no corresponde necesariamente con la producción de toxinas. Por otra parte, el uso de GFBM facilita la generación de hipótesis y resume la información de muchas especies sin llegar a su identificación, siendo aplicable por no expertos en taxonomía. No obstante, el conteo y la estimación de biovolumen son costosos en horas de trabajo de técnicos especializados y la presencia de GFBM, al igual que las especies, no da cuenta de la toxicidad. Una alternativa para la mejora de este aspecto es automatizar el conteo en imágenes digitales, lo cual es más fácil si se trata de identificar grupos basados en morfología. A su vez, las herramientas moleculares poseen una gran sensibilidad y abarcan el potencial tóxico de una muestra, sin embargo, el hecho de que exista el potencial genómico no necesariamente implica que los organismos estén efectivamente produciendo la toxina. $\mathrm{Si}$ bien este tipo de técnicas requiere equipamiento especializado, su alta sensibilidad, la posibilidad de analizar varias muestras a la vez y el corto tiempo necesario para obtener resultados las convierten en una herramienta promisoria para el monitoreo, especialmente de agua destinada al consumo humano. En este sentido, sería necesario evaluar la expresión de los genes, aunque estudios preliminares sugieren que su expresión es constitutiva (Martínez de la Escalera, comunicación personal).

\section{Relación entre los distintos indicadores analizados}

En general se encontró una concordancia entre los indicadores tradicionales y las nuevas herramientas desarrolladas en este trabajo en mostrar la presencia de condiciones avanzadas de floraciones de cianobacterias o altas biomasas de las mismas. La clorofila-a tuvo en muchos casos valores relativamente bajos, mientras que en el otro extremo la abundancia de genes tuvo una mucho mayor sensibilidad y, por lo tanto, mayor potencial para la detección de estos organismos en bajas concentraciones. En presencia de floraciones como manchas, todos los indicadores coincidieron, ya que en estas condiciones las cianobacterias son las que más aportan a este indicador de fitoplancton. En presencia de colonias, la clorofila-a o el biovolumen total no fueron sensibles, y estarían indicando buena calidad cuando en realidad existe la potencialidad de floraciones nocivas. Esto se debe a que estos indicadores incluyen además de las cianobacterias a todos los demás organismos del fitoplancton. Por estas razones se está utilizando en la literatura internacional y en las normativas de otros países la combinación de indicadores, por ejemplo, biovolumen, clorofila-a, presencia de especies potencialmente tóxicas y su biovolumen, conjuntamente con la presencia de toxinas en el agua (Chorus, 2012).

Se utilizó la relación entre la concentración total de genes $m c y$ y el biovolumen del grupo VII como indicador de la proporción de organismos con el potencial real de producir toxinas. Cabe destacar que si bien el género Microcystis fue el más abundante en este grupo, existieron varias especies y otros géneros que son similares morfológicamente y que producen la toxina. Esta relación fue mayor en Salto y disminuyó hacia Punta del Este, donde si bien fue indetectable por las metodologías tradicionales fue cuantificable utilizando redes de arrastre. Este indicador fue positivo en más casos que la concentración de microcistinas-LR. Esto, además de estar asociado a la sensibilidad del método, podría ser el resultado de la presencia de muchas otras variedades de microcistinas, lo cual coincide además con el elevado número de especies del grupo VII registradas.

\section{Propuesta de monitoreo adaptativo del Complejo Microcystis aeruginosa (CMA)}

Los «árboles de decisión» permiten instrumentar medidas de acuerdo a cada situación particular y han sido incorporados eficazmente, por ejemplo en la reglamentación de Brasil (Cybis, et al., 2006). La combinación de distintos estimadores desde los más robustos hasta los más sensibles mejora los resultados de los sistemas de vigilancia y monitoreos, sobre todo en el poder de predicción y la toma de medidas adecuadas. De esta manera se podría evitar generar alertas cuando la composición de la comunidad no es tóxica, aunque el indicador global indique posibles problemas o no actuar cuando su sensibilidad es mala y, sin embargo, existan organismos tóxicos en el agua. El sistema de monitoreo y alerta desarrollado apunta a la vigilancia de uno de los grupos formadores de floraciones más comunes en Uruguay y el mundo, el CMA, el cual tiene la ventaja de alcanzar grandes tamaños. Como se ha mencionado, existen otros grupos formadores de floraciones muy relevantes, como el grupo III, que incluye especies filamentosas como Dolichospermum. Las herramientas desarrolladas son aplicables a este tipo de organismos pero 
con algunas modificaciones. Por ejemplo, para el monitoreo de este grupo de menor tamaño sería necesario utilizar redes de menor poro y considerar los genes que codifican para saxitoxinas. En este sentido, se prevé como perspectiva de este trabajo el ajuste de las herramientas diseñadas para monitorear este tipo de floraciones.

\section{Reconocimientos}

El proyecto fue aprobado el 19/4/2012, como resultado de la convocatoria del Programa de Medio Ambiente - LATU ANII (Modalidad I: Proyectos de Investigación Aplicada) y cuenta con la cooperación del Instituto Clemente Estable, de la Facultad de Ciencias y el CURE Rocha UdelaR. El programa CSIC Grupos I+D (UdelaR) contribuyó con la ejecución de esta investigación. Se agradece especialmente la colaboración de la Asociación Honoraria de Salvamentos Marítimos y Fluviales (ADES) y a la Comisión Técnica Mixta de Salto Grande (CTM) por permitirnos realizar los muestreos en sus embarcaciones y darnos espacio para el análisis in situ de las muestras. Agradecemos también al Liceo número 2 de Carmelo por facilitarnos espacio de laboratorio.

\section{Referencias}

Acha, E.M., Mianzan, H., Guerrero, R., Carreto, J., Giberto, D., Montoya, N. y Carignan, M., 2008. An overview of physical and ecological processes in the Rio de la Plata Estuary. En: Continental Shelf Research, 28(13), pp.15791588.

Aubriot, L., Bonilla, S. y Kruk, C., 2009. Cianobacterias: factores que regulan su crecimiento. En: Bonilla, S., (ed.). Cianobacterias. Manual para la identificación y monitoreo. Montevideo: UNESCO. pp.5-11.

Bittencourt-Oliveira, M.C., 2003. Detection of potential microcystin-producing cyanobacteria in Brazilian reservoirs with a mcyB molecular marker. En: Harmful Algae, 2(1), pp.51-60.

Bonilla, S., 2009. Cianobacterias. Manual para Identificación y Monitoreo. Montevideo: Unesco. ISBN: 978-92-9089-138-3

Bonilla, S., Aubriot, L., Soares, M.C.S., González-Piana, M., Fabre, A., Huszar, V.L.M., Lürling, M., Antoniades, D., Padisák, J. y Kruk, C., 2011. What drives the distribution of the bloom forming cyanobacteria Planktothrix agardhii and Cylindrospermopsis raciborskii? En: FEMS Microbiology Ecology, 79(3), pp.594-607.

Borics, G., Görgényi, J., Grigorszky, I., László-Nagy, Z., Tóthmérész, B., Krasznai, E. y Várbíró, G., 2014. The role of phytoplankton diversity metrics in shallow lake and river quality assessment. En: Ecological Indicators, 45, pp.28-36.

Brena, B. y Bonilla, S., 2009. Producción de toxinas y otros metabolitos. En: Bonilla, S., (ed.). Cianobacterias planctónicas del Uruguay: Manual para la identificación $y$ medidas de gestión. Montevideo: UNESCO. pp.16-18. (Documento Técnico PHI,16)

Cabrera, C., 2011. Efectos de las variaciones en el fotoperíodo en la comunidad fitoplanctónica: un enfoque funcional. Montevideo: Facultad de Ciencias - Universidad de la República. (Tesina Licenciatura en Ciencias Biológicas).

Cabrera, C., Rodríguez-Gallego, L. y Kruk, C., 2013. Efecto de la salinidad y la concentración de nutrientes en las floraciones de cianobacterias de una laguna costera de Uruguay. En: Cirelli, A.F., Carrera, A.P. y Volpedo, A., (eds.). El agua en la producción agropecuaria. II Jornadas Interdisciplinarias Ciclo del Agua en Agroecosistemas. Buenos Aires: Centro de Estudios Transdisciplinarios del Agua de la UBA. pp.55-71.

Calliari, D., Gómez, M. y Gómez, N., 2005. Biomass and composition of the phytoplankton in the Río de la Plata: large-scale distribution and relationship with environmental variables during a spring cruise. En: Continental Shelf Research, 25(2), pp.197-210.

Conde, D., Arocena, R. y Rodríguez-Gallego, L., 2002a. Recursos acuáticos superficiales de Uruguay: ambientes algunas problemáticas y desafíos para la gestión (I). En: AMBIOS, III(10), pp.5-9.

Conde, D., Arocena, R. y Rodríguez-Gallego, L., 2002b. Recursos acuáticos superficiales de Uruguay: ambientes algunas problemáticas y desafíos para la gestión (II). En: AMBIOS, IV(11), pp.32-33.

Cybis, L.F., Bendati, M.M., Marodin Maizonave, C.R., Werner, V.R. y Domingues, C.D., 2006. Manual para estudo de cianobactérias planctonicas em manaciais de abastecimento público: caso da represa Lomba do Sabao e lago Guaíba, Porto Alegre, Rio Grande do Sul. Puerto Alegre: PROSAB. ISBN: 85-7022-153-3.

Chalar, G., 2009. The use of phytoplankton patterns of diversity for algal bloom management. En: Limnologica, 39(3), pp.200-208.

Chorus, I., 2012. Current approaches to Cyanotoxin risk assessment, risk management and regulations in different countries. Dessau-Roßlau: Federal Environment Agency (Umweltbundesamt). ISBN: 1862-4804.

Chorus, I. y Bartram, J., 1999. Toxic cyanobacteria in water. A guide to their public health consequences, monitoring and managment. London: Chapman \& Hall. ISBN: 0-41923930-8.

De León, L. y Yunes, J.S., 2001. First report of a Microcystincontaining bloom of the cyanobacterium Microcystis aeruginosa in the La Plata River, South America. En: Environmental Toxicology, 16(1), pp.110-112.

DINAMA, 2009. Floración de Cianobacterias del río Uruguay el 4 de febrero de 2009. Montevideo: MVOTMA. pp.40.

Dittmanna, E. y Börner, T., 2005. Genetic contributions to the risk assessment of microcystin in the environment. En: Toxicology and Applied Pharmacology, 203(3), pp.192-200.

Ferrari, G., 2008. Fitoplancton del estuario del Río de la Plata y frente oceánico. Montevideo: Facultad de Ciencias Universidad de la República. (Tesis de Maestría).

Ferrari, G. y Pérez, M.C., 2002. Fitoplancton de la costa platense y atlántica de Uruguay, 1993-1994. En: Iheringia Série Botanica, 57(2), pp.263-278.

Ferrari, G., Pérez, M.C., Dabezies, M., Míguez, D. y Saizar, C., 2011. Planktic cyanobacteria in the lower Uruguay River, South America. En: Fottea, 11(1), pp.225-234.

Framiñan, M. y Brown, O., 1996. Study of the Río de la Plata turbidity front. Part I: Spatial and temporal distribution. En: Continental Shelf Research, 16(10), pp.1259-1282.

Furukawa, K., Noda, N., Tsuneda, S., Saito, T., Itayama, T. y Inamori, Y., 2006. Highly sensitive real-time PCR assay for quantification of toxic cyanobacteria based on microcystin synthetase a gene. En: Journal of Bioscience and Bioingeniery, 102(2), pp.90-96.

García-Rodríguez, F., Brugnoli, E., Muniz, P., Venturini, 
N., Burone, L., Hutton, M., Rodríguez, M., Pita, A., Kandratavicius, N., Pérez, L. y Verocai, J., 2013. Warmphase ENSO events modulate the continental freshwater input and the trophic state of sediments in a large South American estuary. En: Marine and Freshwater Research, 64(1), pp.1-11.

García, M.D. y Bonel, N., 2014. Environmental modulation of the plankton community composition and size-structure along the eutrophic intertidal coast of the Río de la Plata estuary, Argentina. En: Journal of Limnology, 73(3), pp.562-573.

Gómez, N., Hualde, P.R., Licursi, M. y Bauer, D.E., 2004. Spring phytoplankton of Río de la Plata: a temperate estuary of South America. En: Estuarine, Coastal and Shelf Science, 61(2), pp.301-309.

González-Piana, M., Fabian, D., Delbene, L. y Chalar, G., 2011. Toxics blooms of Microcystis aeruginosa in three Río Negro reservoirs, Uruguay. En: Harmful algae news, 43, pp.16-17.

Guerrero, R.A., Acha, E.M., Framiñan, M.B. y Lasta, C.A., 1997. Physical oceanography of the Rio de la Plata Estuary, Argentina. En: Continental Shelf Research, 17(7), pp.727-742.

Hillebrand, H., Dürselen, C., Kirschtel, D., Zohary, T. y Pollingher, U., 1999. Biovolume calculation for pelagic and benthic microalgae. En: Journal of Phycology, 35(2), pp.403-424.

Huisman, J. y Hulot, F.D., 2005. Population dynamics of harmful cyanobacteria. En: Huisman, J., Matthijs, H.C.P. y Visser, P.M., (eds.). Harmful Cyanobacteria. The Netherlands: Springer. pp.143-176.

Huisman, J. y Weissing, F.J., 2001. Fundamental unpredictability in multispecies competition. En: The American Naturalist, 157(5), pp.488-494.

Humbert, J.F., Quiblier, C. y Gugger, M., 2010. Molecular approaches for monitoring potentially toxic marine and freshwater phytoplankton species. En: Analytical and Bioanalytical Chemistry, 397(5), pp.1723-1732.

International Organization for Standarization, 1997. ISO/TR 11905-2: Water quality - Determination of nitrogen - Part 2: Determination of bound nitrogen, after combustion and oxidation to nitrogen dioxide, chemiluminescence detection. Ginebra: ISO.

International Organization for Standarization, 2005. ISO 20179: Water quality - Determination of microcystins - Method using solid phase extraction (SPE) and high performance liquid chromatography (HPLC) with ultraviolet (UV) detection. Ginebra: ISO.

Jespersen, A.-M. y Christoffersen, K., 1987. Measurements of chlorophyll-a from phytoplankton using ethanol as extraction solvent. En: Archiv für Hydrobiologie, 109(3), pp.445-454.

Komárek, J. y Komárková, J., 2003. Phenotype diversity of the cyanoprokaryotic genus Cylindrospermopsis (Nostocales); review 2002. En: Czech Phycology, 3(1), pp.1-30.

Kruk, C. y De León, L., 2002. Asociaciones de fitoplancton en lagos y embalses del Uruguay: validación y aplicación a la gestión de sistemas acuáticos. En: Fernández-Cirelli, A. y Chalar, G., (eds.). El agua en Iberoamérica: de la limnología a la gestión en Sudamérica. Buenos Aires: CYTED XVII, CETA. pp.143-155.

Kruk, C., Vidal, L., Aubriot, L., Bonilla, S., Brena, B., 2009. Metodologías de análisis de cianobacterias. Capítulo 5. En: Bonilla, S. Cianobacterias planctónicas del Uruguay: manual para la identificación y medidas de gestión. Montevideo: UNESCO. pp. 19-26. (Documento Técnico PHI No 16)

Kruk, C., Huszar, V.L.M., Peeters, E.T.H.M., Bonilla, S., Costa, L., Lürling, M., Reynolds, C.S. y Scheffer, M., 2010. A morphological classification capturing functional variation in phytoplankton. En: Freshwater Biology, 55(3), pp.614-627.

Kruk, C., Martínez, A., Nogueira, L., Alonso, C. y Calliari, D., 2014. Morphological traits variability reflects light limitation of phytoplankton production in a highly productive subtropical estuary (Río de la Plata, South America) En: Marine Biology, 162(2), pp.331-341.

Kruk, C., Peeters, E.T.H.M., Van Nes, E.H., Huszar, V.L.M., Costa, L.S. y Scheffer, M., 2011. Phytoplankton community composition can be predicted best in terms of morphological groups. En: Limnology and Oceanography, 56(1), pp.110-118.

Kruk, C. y Segura, A., 2012. The habitat template of phytoplankton morphology-based functional groups. En: Hydrobiologia, 698(1), pp.191-202.

Kruk, C., Segura, A.M., Peeters, E.T.H.M., Huszar, V.L.M., Costa, L.S., Kosten, S., Lacerot, G. y Scheffer, M., 2012. Phytoplankton species predictability increases towards warmer regions. En: Limnology and Oceanography, 57(4), pp.1126-1135.

Lachat Instruments, 2009. Determination of total phosphorus in brackish and fresh waters by flow Injection Analysis. Milwaukee: Lachat Instruments. Method 31-115-01-3-D.

Lawton, L.A., Edwards, C. y Codd, G.A., 1994. Extraction y high-performance liquid chromatographic method for the determination of microcystins in raw y treated waters. En: Analyst, 119(7), pp.1525-1530.

Le Quéré, C., Harrison, S.P., Prentice, I.C., Buitenhuis, E.T., Aumont, O., Bopp, L., Claustre, H., Da Cunha, L.C., Geider, R., Giraud, X., Klaas, C., Kohfeld, K.E., Legendre, L., Manizza, M., Platt, T., Rivkin, R.B., Sathyendranath, S., Uitz, J., Watson, A.J. y Wolf-Gladrow, D., 2005. Ecosystem dynamics based on plankton functional types for global ocean biogeochemistry models. En: Global Change Biology, 11(11), pp.2016-2040.

Martigani, F., 2012. Influencia de la deficiencia por nutrientes en el crecimiento y la producción de toxinas de una cianobacteria invasora. Montevideo: Facultad de Ciencias - Universidad de la República. (Tesis de Licenciatura en Ciencias Biológicas).

Mazzeo, N., Clemente, J., García-Rodríguez, F., Gorga, J., Kruk, C., Larrea, D., Meerhoff, M., Quintans, F., Rodríguez-Gallego, L. y Scasso, F., 2002. Eutrofización: causas, consecuencias y manejo. En: Domínguez, A. y Prieto, R.G., (eds.). Perfil Ambiental del Uruguay. Montevideo: Nordan-Comunidad. pp.39-56.

Mc Gill, B., Enquist, B.J., Weiher, E. y Westoby, M., 2006. Rebuilding community ecology from functional traits. En: Trends in Ecology and Evolution, 21(4), pp.178-185.

Mianzan, H.W., Lasta, C., Acha, E.M., Guerrero, R., Machi, G. y Bremec, C., 2001. The Río de la Plata Estuary, Argentina, Uruguay. En: Seeliger, U., de Lacerda, L. y Kjerve, B., (eds.). Ecological studies: coastal marine ecosistems of Latin America. Berlin: Springer. pp.185-204.

Muniz, P., Venturini, N., Hutton, M., Kandratavicius, N., Pita, A., Brugnoli, E., Burone, L. y García-Rodríguez, F., 2011. Ecosystem health of Montevideo coastal zone: A multi approach using some different benthic indicators 
to improve a ten-year-ago assessment. En: Journal of Sea Research, 65(1), pp.38-50.

O’Farrell, I., de Tezanos Pinto, P. y Izaguirre, I., 2007. Phytoplankton morphological response to the underwater light conditions in a vegetated wetland. En: Hydrobiologia, 578, pp.65-77.

O'Farrell, I., Bordet, F. y Chaparro, G., 2012. Bloom forming cyanobacterial complexes co-occurring in a subtropical large reservoir: validation of dominant eco-strategies. En: Hydrobiologia, 698(1), pp.175-190.

OSE, 2009. Informe del comportamiento de las cianobacterias en el agua bruta de Fray Bentos. Montevideo: Obras Sanitarias del Estado. pp.26.

Otsuka, S., Suda, S., Li, R., Matsumoto, S. y Watanabe, M.M., 2000. Morphological variability of colonies of Microcystis morphospecies in culture. En: The Journal of General and Applied Microbiology, 46(1), pp.39-50.

Otsuka, S., Suda, S., Li, R., Watanabe, M., Oyaizu, H., Matsumoto, S. y Watanabe, M.M., 1999. Characterization of morphospecies and strains of the genus Microcystis (Cyanobacteria) for a reconsideration of species classification. En: Phycological Research, 47(3), pp.189-197.

Padisák, J., Crossetti, L.O. y Naselli-Flores, L., 2009. Use and misuse in the application of the phytoplankton functional classification: a critical review with updates. En: Hydrobiologia, 621(1), pp.1-19.

Paerl, H. y Huisman, J., 2008. Blooms Like It Hot. En: Science, 320(5872), pp.57-58.

Paerl, H.W. y Huisman, J., 2009. Minireview climate change: A catalyst for global expansion of harmful cyanobacterial blooms. En: Environmental Microbiology Reports, 1, pp.27-37.

Pearson, L.A. y Neilan, B.A., 2008. The molecular genetics of cyanobacterial toxicity as a basis for monitoring water quality and public health risk. En: Current Opinion in Biotechnology, 19(3), pp.281-288.

Pérez, M.C., Bonilla, S. y Martínez, G., 1999. Phytoplankton community of a polymictic reservoir, La Plata River basin, Uruguay. En: Revista Brasileira de Biologia, 59(4), pp.535-541.

Piccini, C., Aubriot, L., D’Alessandro, B., Martigani, F. y Bonilla, S., 2013. Revealing toxin signatures in cyanobacteria: report of genes involved in cylindrospermopsin synthesis from saxitoxin-producing Cylindrospermopsis raciborski. En: Advances in Microbiology, 3(3), pp.289-296.

Piccini, C., Aubriot, L., Fabre, A., Amaral, V., GonzálezPiana, M., Giani, A., Figueredo, C.C., Vidal, L., Kruk, C. y Bonilla, S., 2011. Genetic and eco-physiological differences of South American Cylindrospermopsis raciborskii isolates support the hypothesis of multiple ecotypes. En: Harmful Algae, 10(6), pp.644-653.

R Core Team, 2013. R: A language and environment for statistical computing $R$ Foundation for Statistical Computing, Vienna, Austria [En línea]. [Consulta: 14/5/2015]. Disponible en: http://www.R-project.org/.

Reynolds, C., Huszar, V., Kruk, C., Naselli-Flores, L. y Melo, S., 2002. Towards a functional classification of the freshwater phytoplankton. En: Journal of Plankton Research, 24(5), pp.417-428.

Reynolds, C.S., 2002. Ecological pattern and ecosystem theory. En: Ecological Modelling, 158(3), pp.181-200.

Reynolds, C.S., 2006. Ecology of phytoplankton. Cambridge: Cambridge University Press. ISBN: 9780521605199.

Reynolds, C.S., 2007. Variability in the provision and function of mucilage in phytoplankton: facultative responses to the environment. En: Hydrobiologia, 578(1), pp.37-45.

Reynolds, C.S., 2012. Environmental requirements and habitat preferences of phytoplankton: chance and certainty in species selection. En: Botanica Marina, 55(1), pp.1-17.

Reynolds, C.S., Jawroski, G.H.M., Cmieche, H.A. y Leedale, G.F., 1981. On the annual cycle of the blue-green alga M. aeruginosa Kütz. Emend. Elenkin. En: Philosophical Transactions of The Royal Society B Biological Sciences, 293(1068), pp.419-477.

Reynolds, C.S. y Walsby, A.E., 1975. Water-blooms. En: Biological Reviews, 50(4), pp.437-481.

Rodríguez-Gallego, L., 2010. Eutrofización de las lagunas costeras de Uruguay: impacto y optimización de los usos del suelo. Montevideo: Facultad de Ciencias - Universidad de la República. (Tesis de Doctorado).

Saizar, C., Míguez, D., Dabezies, M., Teixeira De Mello, F., Clemente, J., Ferrari, G., Boccardi, L. y Tana, J., 2011. Línea de base para evaluar el impacto de una planta de celulosa en el Río Uruguay. En: INNOTEC, 5, pp.11-22.

Salas, H. y Martino, P., 1991. A simplified phosphorous trophic state model for warm-water tropical state. En: Water Research, 25(3), pp.341-350.

Sarthou, F., Cabrera, C. y Nogueira, L. 2009. Grupos morfofuncionales para evaluar el riesgo de ocurrencia de floraciones: aproximación matemática y experimental. Montevideo: PAIE-CSIC-UDELAR. (Trabajo de Iniciación a la investigación).

Sathicq, M.B., Gómez, N., Andrinolo, D., Sedán, D. y Donadelli, J.L., 2014. Temporal distribution of cyanobacteria in the coast of a shallow temperate estuary (Río de la Plata): some implications for its monitoring. En: Enviromental Monitoring and Assessment, 186(11), pp.7115-7125.

Scheffer, M., Rinaldi, S., Huisman, J. y Weissing, F.J., 2003. Why plankton communities have no equilibrium: solutions to the paradox. En: Hydrobiologia, 491(1-3), pp.9-18.

Segura, A., Kruk, C., Calliari, D. y Fort, H., 2013. Use of a morphology-based functional approach to model phytoplankton community succession in a shallow subtropical lake. En: Freshwater Biology, 58(3), pp.504-512.

Smayda, T.J., 1997. What is a bloom? En: Limnology and Oceanography, 42(5), pp.1132-1136.

Uruguay. Decreto 253/979, de 19 de mayo de 1979. Diario Oficial, 31 de mayo de 1979, p.1473.

Vidal, L. y Britos, A., 2012. Uruguay: occurrence, toxicity and regulation of Cyanobacteria. En: Chorus, I., (ed.). Current approaches to Cyanotoxin risk assessment, risk management and regulations in different countries. Dessau-Roßlau: Federal Environment Agency (Umweltbundesamt). pp.130-136.

Vidal, L. y Kruk, C., 2008. Cylindrospermopsis raciborskii (Cyanobacteria) extends its distribution to Latitude $34^{\circ} 53^{\prime} \mathrm{S}$ : taxonomical and ecological features in Uruguayan eutrophic lakes. En: Pan-American Journal of Aquatic Sciences, 3(2), pp.142-151.

Vizziano, D., Saona, G., Franco, J. y Nagy, G.J., 2001. Caracterización ambiental del área de desove de la corvina blanca Micropogonias furnieri en la zona frontal del Río de la Plata. En: Mesones, V.P. y Nagy, G.J., (eds.). El Río de la Plata. Investigación para la gestión del ambiente, los recursos pesqueros y la pesquería en el frente salino. 
Montevideo: Ecoplata. pp.115-128.

Vollenweider, R.A., 1976. Advances in defining critical loading levels for phosphorus in lake eutrophication. En: Memorie dell'Istituto Italiano di Idrobiologia, Dott. Marco de Marchi Verbania Pallanza, 33, pp.53-83.

Whitton, B.A. y Potts, M., 2000. The ecology of cyanobacteria. Dordrecth: Kluwer Academic Publishers. ISBN: 978-0306-46855-1.
Wu, T., Qin, B., Brookes, J.D., Shi, K., Zhu, G., Zhu, M., Yan, W. y Wang, Z., 2015. The influence of changes in wind patterns on the areal extension of surface cyanobacterial blooms in a large shallow lake in China. En: The Science of Total Environment, 518-519, pp.24-30.

Zhou, J., Bruns, M.A. y Tiedje, J.M., 1996. En: American Society for Microbiology DNA Recovery from Soils of Diverse Composition, 62(2), pp.316-322. 